\title{
EVOLUCIÓN Y ESTRUCTURA DE LOS MEDIOS DE PAGO DISTINTOS AL EFECTIVO EN MÉXICO
}

\author{
Eduardo Jallath y José Luis Negrín \\ Agosto 2001
}

Documento de Investigación No.2001-04

\author{
Dirección General de Investigación Económica \\ BANCO DE MÉXICO
}

\footnotetext{
* Las opiniones contenidas en este documento corresponden exclusivamente a los autores y no necesariamente representan el punto de vista del Banco de México.

Agradecemos la valiosa colaboración de Clara de la Cerda y los comentarios de Margarita Moleres, Abdón Sánchez y Alejandro Werner. Agradecemos también los comentarios de los asistentes a los seminarios internos del Banco de México.
} 


\title{
Evolución y Estructura de los Medios de Pago Distintos al Efectivo en México
}

\author{
Eduardo Jallath y José Luis Negrín \\ Agosto 2001 \\ Documento de Investigación No.2001-04 \\ Dirección General de Investigación Económica \\ BANCO DE MÉXICO
}

\begin{abstract}
Resumen
En este trabajo se realiza una descripción de la evolución y la estructura de los principales medios de pago distintos al efectivo que se utilizan en México. La descripción incluye medios de pago tradicionales, tales como cheques y tarjetas de crédito, y medios de pago no tradicionales, como transferencias electrónicas y tarjetas de débito. Se aprecia que se ha reducido la importancia de los medios de pago tradicionales mientras que los pagos electrónicos han ganado relevancia tanto en lo que se refiere a pagos de alto volumen como de alto valor. Con respecto a los pagos de alto volumen, las tarjetas de débito han registrado un elevado crecimiento apoyado tanto en el desarrollo de la red de cajeros automáticos, como en su reciente aceptación como medio de pago en puntos de venta. Así, éstos han llegado a representar más de $60 \%$ del número total de transacciones de alto volumen. Adicionalmente, es notable la pérdida de importancia de los cheques tanto en número como en valor de las transacciones. En lo que se refiere a los pagos de alto valor, las transferencias de alto valor (SPEUA) representan mas de 95\% del número de transacciones, mientras que en términos de monto, las transferencias en el sistema de pago de bonos y valores (SIDV), significan más de $60 \%$ del valor total. La comparación de la estructura de los pagos distintos al efectivo de México con aquélla existente en los Estados Unidos y Canadá, refleja que a pesar de la evolución positiva de los pagos electrónicos en México, su uso es aún muy limitado.
\end{abstract}

Clasificación JEL: E5,G1,N2,O3. 


\section{Introducción}

Los medios de pago constituyen la herramienta que los agentes de una economía requieren para transferir valor monetario a fin de pagar por los bienes, servicios y activos financieros que adquieren. Para cualquier economía es fundamental contar con sistemas de pago eficientes y seguros. En la búsqueda de sistemas de pagos eficientes, muchos países se han orientado hacia la rápida adopción de sistemas de pago electrónicos. Las autoridades financieras los han promovido para reducir el riesgo sistémico. ${ }^{1}$ Las instituciones bancarias también los han fomentado para proveer un mejor servicio a sus clientes y para reducir sus costos de transacción. Asimismo, muchas empresas e individuos han adoptado medios de pago electrónicos por su flexibilidad, confiabilidad y conveniencia. Aún más, el desarrollo del Internet y de la "world-wide-web" ha añadido una nueva dimensión al uso de algunos pagos electrónicos tradicionales y ha preparado el terreno para la adopción de nuevos mecanismos tales como el dinero electrónico, los cheques electrónicos y las tarjetas con valor almacenado. De este modo, en la mayor parte de los países en que han sido introducidos, los pagos electrónicos han venido ganando terreno.

Al igual que en otras economías, los medios de pago electrónicos en México han experimentado una alta tasa de adopción. Sin embargo, esta evolución no refleja un proceso puro de adopción de tecnología, sino que se ha visto afectada por las características específicas de la economía mexicana. Entre otras peculiaridades, el sistema financiero mexicano no está al alcance de una importante porción de la población; lo anterior limita el uso de los medios de pago distintos al efectivo, cuya utilización requiere de la participación de intermediarios financieros. Del mismo modo, el sistema legal restringe el desarrollo de algunos medios de pago por la lentitud con que se resuelven las controversias; por tanto, el uso de aquellos medios que involucran un mayor elemento de riesgo, como los cheques, se ve afectado negativamente. Por otra parte, las perturbaciones macroeconómicas, por ejemplo la crisis de 1995, afectaron desfavorablemente el uso de algunos medios de pago, como las tarjetas de crédito. Finalmente, los cambios en la regulación también han influido en el uso de los distintos medios de pago. Por ejemplo, los cambios regulatorios orientados a fomentar la adopción de pagos electrónicos han dado lugar a un

\footnotetext{
${ }^{1}$ En el contexto de sistemas de pago, éste es el riesgo de que la falta de pago oportuno de uno de los participantes del sistema, ocasione que aquellos agentes con quienes el primero tiene obligaciones pendientes tampoco sean capaces de cumplir con sus compromisos. En el extremo, todos los participantes del sistema podrían resultar afectados.
} 
impulso en el uso de las transferencias electrónicas y a un desplazamiento de los cheques de alto valor.

El objetivo de este estudio es efectuar una descripción de la evolución reciente y de la estructura de los medios de pago distintos al efectivo más representativos de México. Así, en este análisis se incluyen medios tradicionales como cheques y tarjetas de crédito, y medios menos tradicionales, como tarjetas de débito y transferencias electrónicas de alto y bajo valor. ${ }^{2}$ Para realizar esta descripción, se presentan brevemente las peculiaridades que los sistemas de pago asociados a los medios analizados han adquirido en México, sin pretender proporcionar una descripción detallada de las características de dichos sistemas. ${ }^{3}$

El período de análisis para la mayor parte de los medios de pago que se estudian, abarca de enero de 1994 a diciembre del 2000. Dicha evolución se presenta tanto para el número como para el valor de las transacciones. Sin realizar un análisis de causalidad formal, para cada instrumento de pago se adelantan hipótesis que explican su trayectoria. Finalmente, sobre la base del desempeño de cada medio, se construye la estructura actual de uso de los mecanismos de pago distintos al efectivo en México. Adicionalmente, en el trabajo se compara la estructura de pagos de México con la de los Estados Unidos y Canadá. Esta comparación proporciona una perspectiva más completa del nivel de desarrollo de los medios de pago en México.

Es conveniente señalar la diferencia conceptual que existe entre sistemas y medios de pago. El sistema de pagos es el conjunto de instrumentos, procedimientos bancarios e infraestructura para transferir fondos entre bancos, que garantiza la circulación de recursos; los medios o instrumentos que los propios agentes utilizan para pagar por los bienes, servicios y activos financieros que adquieren, constituyen componentes centrales de los sistemas de pago. Existe una correspondencia entre el desarrollo de un sistema y el uso de los medios de pago asociados con dicho sistema, pues podría pensarse que los medios fluyen a través de la infraestructura de los sistemas. Este estudio se centra en el uso de distintos medios de pago; para ello, se distingue entre sistemas de pago de alto valor y de alto volumen. Los primeros, también conocidos como de mayoreo, se utilizan

\footnotetext{
${ }^{2}$ Algunos de los medios de pago que no se incluyen son giros telegráficos y postales, órdenes de pago, tarjetas de servicios y tarjetas de tiendas departamentales; estos medios, sin embargo, no parecen tener un gran impacto ni sobre el número ni sobre el monto de las transacciones.

${ }^{3}$ Weiner (1999) presenta una descripción detallada del mecanismo de funcionamiento de distintos sistemas de pago electrónicos.
} 
principalmente para realizar transacciones entre bancos y casas de bolsa. Como su nombre lo indica, el valor promedio de estas transacciones es elevado. En el caso de México, las transacciones de alto valor se canalizan a través de tres sistemas de pago especializados, todos ellos conectados entre sí. Existe un sistema que opera principalmente transacciones entre bancos y casa de bolsa (Sistema de Atención a Cuentahabientes, SIAC); otro sistema permite dar servicio a clientes de los bancos (Sistema de Pagos Electrónicos de Uso Ampliado, SPEUA); y se cuenta con un sistema específico para transacciones de bonos y valores (Sistema de Información de Depósito de Valores, SIDV). El funcionamiento de estos sistemas constituye una preocupación importante de la banca central, por lo cual se han establecido reglas que garantizan la liquidez ${ }^{4}$ y que promueven la seguridad de los mismos.

Por su parte, los medios de pago de alto volumen, conocidos como al menudeo, procesan pagos entre consumidores y negocios, con la intervención de intermediarios financieros, cuyos montos son relativamente bajos. En este trabajo se presenta la evolución de cheques, tarjetas de débito, tarjetas de crédito y del Pago Interbancario. Adicionalmente, como punto de referencia, se presentan indicadores indirectos del uso de efectivo y se analiza el desarrollo de la red de cajeros automáticos.

Entre los hallazgos de este trabajo, se observa que se ha reducido la importancia de los medios de pago tradicionales distintos al efectivo, mientras que los pagos menos tradicionales han ganado participación en el mercado. En el caso de los pagos de alto volumen, las tarjetas de débito han registrado un elevado crecimiento apoyado tanto en el desarrollo de la red de cajeros automáticos, como en su reciente aceptación como medio de pago en puntos de venta. Del mismo modo, los pagos interbancarios han experimentado un incremento significativo. En el caso de los cheques es notable la pérdida de importancia tanto en el número como en el valor de las transacciones. En lo que se refiere al número de transacciones de alto valor, las transferencias por SPEUA representan más de 95\% del total, mientras que en términos de valor, las transacciones en el SIDV representan más de $60 \%$ del valor total. La comparación de la estructura de los pagos distintos al efectivo de México con aquélla existente en los Estados Unidos y Canadá, refleja un uso muy limitado de los

\footnotetext{
${ }^{4}$ Los sistemas de pago suelen enfrentar un riesgo de liquidez. Dicho riesgo ocurre cuando alguno de los participantes no tiene los fondos comprometidos en el momento de la liquidación, aunque podría contar con ellos posteriormente. En algunos casos el banco central y en otros los demás participantes, otorgan crédito para garantizar que el sistema posee un nivel adecuado de liquidez.
} 
mismos, aún corrigiendo por el tamaño de la economía y por el número de habitantes. Esto ocurre a pesar de la favorable evolución de los pagos electrónicos en México en los últimos años. Sin embargo, el menor uso relativo se puede atribuir más a la falta de profundidad del sistema financiero mexicano que al nivel de desarrollo de los medios de pago. Es decir, los medios de pago distintos al efectivo no pueden tener una penetración mayor a la que tienen las instituciones financieras en México.

Este trabajo está organizado de la siguiente forma. La segunda sección se ocupa de describir la evolución de los pagos de alto volumen, incluyendo un breve análisis del uso de efectivo y del funcionamiento de la red de cajeros automáticos. La tercera sección describe las tendencias de los medios de pago de alto valor. La cuarta sección presenta la estructura de los medios de pago distintos al efectivo, tanto para alto volumen como para alto valor. También incluye una comparación de la estructura de los medios de pago en México con la de los Estados Unidos y Canadá. La quinta sección presenta las conclusiones del trabajo.

\section{Sistemas de Pago de Alto Volumen}

En esta sección se presenta la evolución de los sistemas de pago de alto volumen. Estos sistemas, también denominados al menudeo, procesan pagos de relativamente bajo valor, que se realizan entre consumidores o entre consumidores y negocios. Los medios que se estudian en esta sección son cheques, tarjetas de crédito, tarjetas de débito y Pago Interbancario. ${ }^{5}$ Los cheques y las tarjetas de crédito son los medios de pago distintos al efectivo más tradicionales; sin embargo, su uso nunca ha sido muy extenso entre la población. Ello parece relacionarse con el nivel de riesgo ${ }^{6}$ que su uso implica y con el sistema legal mexicano, el cual no permite una pronta resolución de los problemas de pago. En contraste, el uso de medios de reciente introducción como las tarjetas de

\footnotetext{
${ }^{5}$ Entre los medios de pago de alto volumen, además de las tarjetas de crédito y débito bancarias, es importante mencionar al menos otros dos tipos de tarjetas. El primero lo conforman las tarjetas de crédito emitidas por tiendas departamentales cuyo uso está restringido a transacciones en las tiendas emisoras. El segundo está constituido por las tarjetas de servicios, tales como Dinner's Club y una proporción importante de las tarjetas American Express, las cuales no proveen crédito y deben ser liquidadas a fin de mes. No se cuenta con datos de este tipo de tarjetas; sin embargo, alguna evidencia sugiere que las tarjetas de servicios han perdido terreno frente al crecimiento de las tarjetas de débito. Tampoco se incluyen los giros postales y telegráficos, cuya importancia también ha declinado en los últimos años.

${ }^{6}$ Las tarjetas de crédito y los cheques incurren en un tipo de riesgo distinto. En el caso de los cheques, el receptor del pago incurre en el riesgo de que el emisor del cheque carezca de fondos en su cuenta. En cuanto a las tarjetas de crédito, el receptor del pago no es quien corre el riesgo, sino el banco emisor de la tarjeta. En este caso, el tarjetahabiente podría no pagar su deuda con el banco emisor. A pesar de esta diferencia, en ambos casos se enfrentan dificultades similares para la solución de controversias en el ámbito legal.
} 
débito y los Pagos Interbancarios - cuyas características intrínsecas generan un riesgo menor - se ha incrementado en forma significativa. Dicho incremento es relativo, pues el mayor uso de los sistemas de pago distintos al efectivo continúa estando limitado por el acceso al sistema financiero mexicano. Como complemento al análisis de los medio de pago de alto volumen, se incluye una breve descripción de la importancia del uso de efectivo en México y de la evolución de las transacciones en la red de cajeros automáticos (ATM). Aunque los cajeros automáticos no constituyen un medio de pago en sí, el desarrollo de esta red sin duda afecta el uso de varios medios de pago.

\subsection{Efectivo}

El efectivo es el medio de pago más tradicional en el mundo. A pesar ello, tanto en México como en la mayor parte de los países, la información sobre el valor y el número de las transacciones que se realizan en efectivo no está disponible. Este problema se relaciona con la falta de encuestas que permitan el desarrollo de estimaciones adecuadas. Dada esta restricción, en esta sección se presenta un indicador indirecto de la importancia del uso del efectivo para realizar transacciones. Para obtener una mejor idea de la importancia del uso de efectivo en México, se presenta también una comparación internacional.

Las características intrínsecas del efectivo han favorecido su uso para llevar a cabo transacciones. Hancock y Humprey (1998) indican que el efectivo posee varias ventajas sobre otros medios de pago. En primer lugar, el efectivo es muy práctico, es divisible y es aceptado en todas partes. En segundo lugar, las transacciones que se pagan en efectivo, son finales; exceptuando la falsificación, no existe un riesgo adicional en una transacción en efectivo y los recursos pueden ser utilizados de nueva cuenta de inmediato. Esto significa que el efectivo resulta un medio de pago eficiente y seguro para llevar a cabo transacciones de bajo valor. Sin embargo, cuando las transacciones son de un monto considerable, el uso de efectivo presenta ciertas desventajas. En general, no es práctico que los agentes lleven consigo grandes cantidades de efectivo; además, en muchos países esto representa un riesgo para dicho agente. Dadas estas características, algunos estudios para países desarrollados estiman que las transacciones en efectivo representan entre $75 \%$ y 90\% del número de transacciones totales (Boeschoten, 1992). Dicha proporción debería ser aún mayor en los países en desarrollo, donde los medios de pago alternativos fueron introducidos más tarde o han registrado una tasa de aceptación menor. 
Ante las limitaciones existentes en cuanto a información, Hancock y Humphrey (1998) proponen utilizar la razón del efectivo en manos de público no-bancario a oferta monetaria (efectivo/M1) para inferir la importancia de las transacciones en efectivo. Este puede ser un buen indicador del uso de efectivo estrictamente con fines de transacciones, puesto que M1 incluye no solamente efectivo sino también otros depósitos líquidos los cuales sustentan el pago con otros medios.

\section{Cuadro 1}

\begin{tabular}{|c|c|c|c|}
\hline \multicolumn{4}{|c|}{$\begin{array}{c}\text { Efectivo en Poder del Público/M1 } \\
\text { (saldos al fin del período) }\end{array}$} \\
\hline & 1994 & 2000 & Variación (\%) \\
\hline Alemania & 33.1 & 24.3 & -26.5 \\
\hline Argentina & 68.6 & 63.0 & -8.3 \\
\hline Bélgica & 28.0 & 20.1 & -28.1 \\
\hline Brasil & 38.3 & 38.7 & 1.2 \\
\hline Canadá & 21.8 & 16.1 & -26.3 \\
\hline Chile & 35.3 & 43.1 & 22.2 \\
\hline Colombia & 37.0 & 45.8 & 23.8 \\
\hline Estados Unidos de América (EUA) & 31.0 & 49.2 & 59.0 \\
\hline Francia & 16.2 & 15.6 & -3.4 \\
\hline Italia & 17.5 & 15.8 & -10.0 \\
\hline Japón & 27.9 & 25.0 & -10.4 \\
\hline México & 31.8 & 32.4 & 2.0 \\
\hline Suiza & 34.4 & 23.6 & -31.4 \\
\hline Venezuela & 28.4 & 21.0 & -25.9 \\
\hline Promedio & 32.1 & 31.0 & -3.4 \\
\hline Promedio sin los EUA & 32.2 & 29.6 & -8.1 \\
\hline Promedio Países Desarrollados & 26.2 & 23.7 & -9.6 \\
\hline Promedio Países Desarrollados sin los EUA & 25.6 & 20.1 & -21.5 \\
\hline Promedio Países Latinos & 39.9 & 40.7 & 2.0 \\
\hline Promedio Latinos sin Argentina & 34.1 & 36.2 & 6.1 \\
\hline \multicolumn{4}{|c|}{$\begin{array}{l}\text { Fuente: FMI, Estadísticas Financieras Internacionales (EFI). } \\
\text { Para efectivo se utilizó la línea 14a de las EFI, que representa el efectivo fuera de los bancos. } \\
\text { Brasil, Colombia, los Estados Unidos, Francia y México reportan directamente M1. Para los } \\
\text { demás países se utilizó como M1 el rubro } 34 \text { ("dinero", que es igual a la suma del efectivo fuera } \\
\text { de los bancos más los depósitos a la vista de los residentes excepto del gobierno central). Cuando } \\
\text { este rubro no estaba disponible, su utilizó la suma de "dinero en circulación" (línea 34a.n) más } \\
\text { "depósitos a la vista" (línea 34b.n). }\end{array}$} \\
\hline
\end{tabular}

El Cuadro 1 presenta la razón efectivo/M1 para una muestra de 14 países, 8 desarrollados y seis países Latinoamericanos en desarrollo. Pueden observarse dos tendencias principales. La primera es que las transacciones en efectivo son más importantes en países en desarrollo (incluido México) que en países desarrollados; en promedio, los países desarrollados de la muestra registraron una proporción de efectivo/M1 de $31 \%$ en el año 2000, mientras que dicha razón fue de más de $40 \%$ para los países Latinoamericanos. Para el año 2000, tanto los Estados Unidos como Argentina parecen registrar una razón mucho más elevada que el resto de los países incluidos en los dos grupos correspondientes. Excluyendo a los Estados Unidos y a Argentina de los respectivos grupos, el promedio de los países desarrollados cae a $23.7 \%$ mientras que el de los países Latinoamericanos se reduce a 36.2\%. Sin embargo, la brecha entre ambos grupos continúa siendo 
muy amplia. La segunda tendencia que destaca es que de 1994 a 2000, la razón efectivo/M1 se ha reducido en la mayoría de los países desarrollados. Si se excluye a los Estados Unidos, la caída en esa razón es de $21.5 \%$ en promedio en el lapso considerado. En contraste, el promedio de los países latinoamericanos no registra esa disminución. Es decir, si se atribuyera la caída de la razón/M1 de los países desarrollados a la creciente importancia de los medios de pago alternativos al efectivo, ese fenómeno no parecería ocurrir en los países Latinoamericanos, en los cuales el efectivo parece haber mantenido su importancia.

En el caso de México, la razón efectivo/M1 para el año 2000 se mantuvo por arriba de 30\%, el cual es aproximadamente el mismo nivel que registraba en 1994. Dicha razón resultó considerablemente mayor que la registrada en la mayoría de los países desarrollados incluidos en la muestra, tales como Canadá, Francia y Bélgica. Sin embargo, la cifra es inferior a la de los países Latinoamericanos exceptuando a Venezuela. En cualquier caso, el hecho de que la razón efectivo/M1 en México se haya mantenido estable en el lapso considerado, es sorprendente dada la expansión que los pagos distintos al efectivo han registrado, la cual se presenta en las siguientes secciones.

Es interesante destacar también que las tendencias descritas no resultan obvias para el caso de los Estados Unidos debido a la elevada tenencia de dólares americanos en manos de extranjeros, la cual se ha incrementado en los últimos años. ${ }^{7}$ Otro factor que contribuye a explicar el incremento en la razón efectivo/M1 en dicho país, es el acelerado desarrollo de la red de cajeros automáticos. El número de cajeros se duplicó de 1996 a 2000, cuando se introdujeron los cargos por transacción. Aunque este incremento no necesariamente aumenta las tenencias individuales de efectivo, el monto de recursos mantenidos en los cajeros aumenta la cantidad de efectivo fuera de las bóvedas de los bancos.

\subsection{Cajeros Automáticos}

Los cajeros automáticos (ATM) no constituyen un medio de pago, pues no permiten que se realicen pagos entre distintos agentes. Sin embargo, la infraestructura de cajeros puede hacer accesibles las disposiciones de efectivo, por medio, principalmente, de una tarjeta de débito. Los

\footnotetext{
${ }^{7}$ Hancock y Humprey (1998) indican que, en 1993, aproximadamente 65\% de los dólares se encontraba en otros países. Otras estimaciones indican que del total del efectivo emitido por la Reserva Federal de los Estados Unidos, hasta 70\% podría estar fuera del país (US Treasury Department, 2000).
} 
cajeros automáticos tienen un doble efecto en las tenencias de efectivo de los individuos. En primer lugar, les permite mantener un saldo más alto en sus cuentas bancarias por medio del retiro de montos más pequeños con más frecuencia - esto reduciría las tenencias de efectivo. En segundo lugar, les permite un fácil acceso al dinero; es decir, el tamaño de la red de cajeros automáticos guarda una relación directa con la probabilidad de que una transacción se lleve a cabo con efectivo, lo cual aumentaría las tenencias. En todo caso, Hancock y Humprey (1998) demuestran que estos dos efectos se contrarrestan; por tanto, la extensión de la red de cajeros automáticos no parece afectar las tenencias de efectivo individuales. ${ }^{8}$

Una operación particular en un cajero automático, involucra al tarjetahabiente, al banco emisor de la tarjeta, al propio cajero automático -que puede o no ser propiedad del banco que emite la tarjeta- y a la red a la cual tanto el banco emisor como el cajero automático específico están conectados. Los cajeros permiten a los consumidores retirar fondos que son inmediatamente deducidos de sus cuentas bancarias. Aunque la red de cajeros automáticos se expandió en los Estados Unidos desde los años setenta, el sistema financiero mexicano no adoptó dicha tecnología sino hasta principios de los años ochenta. La estructura de cajeros del mercado mexicano es bastante peculiar. Existen tres redes nacionales; los dos bancos más grandes cuentan con su propia red, mientras que la tercera (RED) es manejada por la empresa Prosa, la cual es propiedad del conjunto de los otros bancos de menor tamaño. ${ }^{9}$ Del mismo modo, la mayor parte de los cajeros automáticos son propiedad de los propios bancos. Por tanto, en el sistema financiero mexicano los bancos no solamente emiten las tarjetas, sino que son dueños de la red y de las propias máquinas que constituyen los cajeros automáticos. En la actualidad existen acuerdos de interconexión entre las tres redes mencionadas. ${ }^{10}$ De este modo, en las zonas urbanas existen cajeros automáticos disponibles para cualquier tarjetahabiente en múltiples puntos.

Al igual que en otros países, la red de cajeros automáticos en México se ha extendido rápidamente. De enero de 1994 a diciembre del 2000, el número de terminales de cajeros creció de 4,853 a 17,979. ${ }^{11}$ Esto significa una tasa de crecimiento anual de $23 \%$. Dicha evolución obedece a varios

\footnotetext{
${ }^{8}$ Estos autores llevan a cabo una regresión de corte transversal, para 14 países desarrollados, de tenencias de efectivo contra el número de cajeros automáticos. La regresión resulta en una relación no significativa entre estas variables.

${ }^{9}$ Ver Carnet-Prosa, 1990.

${ }^{10}$ Las propias redes han fijado los términos de tales acuerdos.

${ }^{11}$ El número de cajeros incluye datos de Banamex, Bancomer y Prosa.
} 
factores. En primer lugar, la liberalización de los servicios bancarios incrementó el nivel de competencia en la industria; uno de los instrumentos de competencia que los bancos han utilizado para atraer clientes es la extensión de sus redes de cajeros automáticos. En segundo lugar, conforme ha pasado el tiempo, un mayor número de usuarios se ha dado cuenta de la conveniencia de utilizar esta red y se ha familiarizado con ella. De allí el rápido crecimiento del servicio.

\section{Gráfica 1}

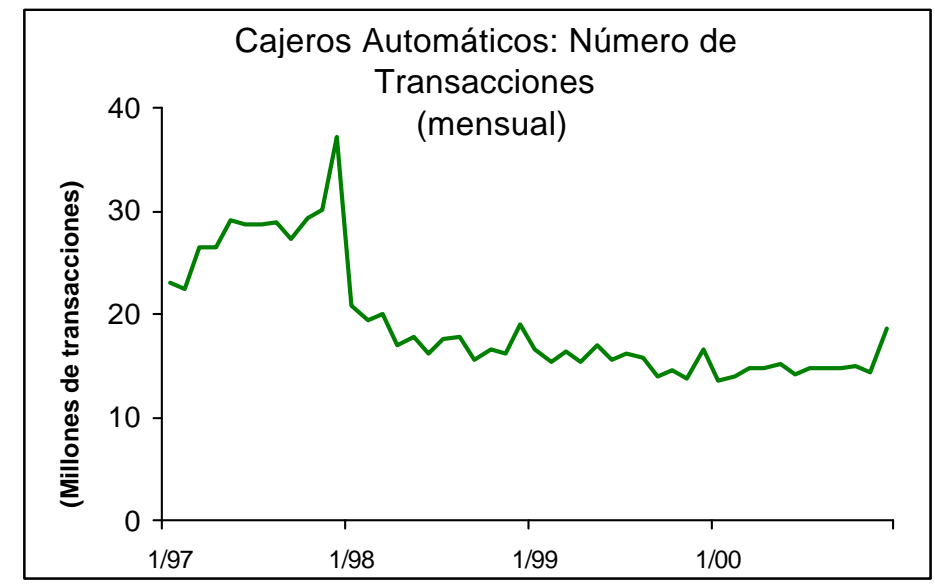

La Gráfica 1 muestra el número de transacciones que se llevaron a cabo en el sistema de cajeros automáticos de México de principios de 1997 a fines del año 2000. ${ }^{12}$ El número de operaciones alcanzó un máximo en 1997; sin embargo, sufrió un fuerte descenso en 1998. Dicha caída podría relacionase con dos factores. En primer lugar, muchos bancos establecieron un cargo por transacción elevando con ello el costo para los usuarios. ${ }^{13}$ En segundo lugar, las tarjetas que con más frecuencia se utilizan en los cajeros, son tarjetas de débito. Dichas tarjetas típicamente están asociadas a alguna cuenta bancaria. Para reducir sus costos de administración, los bancos elevaron el saldo mínimo a mantener en estas cuentas. Luego de la caída registrada en 1997, el número de transacciones se ha estabilizado en alrededor de 16 millones de transacciones al mes.

\footnotetext{
12 Se cuenta directamente con el valor y número de transacciones en cajeros automáticos de RED-Prosa y con el número total de cajeros. En promedio para el año 2000, los cajeros de la RED-Prosa representaron $62 \%$ del total de cajeros del país. Utilizando los datos de RED-Prosa y la proporción de RED-Prosa en el número total de cajeros, se extrapolaron los datos para obtener el número y valor de las transacciones de todo el sistema de cajeros. Para que estos cálculos sean válidos, se está suponiendo que el número y valor de las transacciones realizadas en los cajeros de REDProsa son representativos de todo el sistema. Dada la importancia del número de cajeros de la RED-Prosa en el total, se considera que estas cifras son bastantes representativas.

${ }^{13}$ Los bancos han utilizado diversos esquemas de cobro. El más común ha sido permitir un número de transacciones gratis (entre 5 y 10) y cobrar por las demás.
} 
A pesar de la disminución del número de transacciones observada en 1997, la Gráfica 2 muestra que el valor de las transacciones en cajeros automáticos, expresados en pesos constantes de diciembre de 2000, ha permanecido relativamente estable. Esto indica que, como resultado de la reducción en el número de transacciones, el valor promedio de las transacciones en cajeros automáticos se ha elevado, pasando de 386 pesos (constantes de diciembre del año 2000) en promedio anual en 1997 a 718 pesos en 2000.

\section{Gráfica 2}

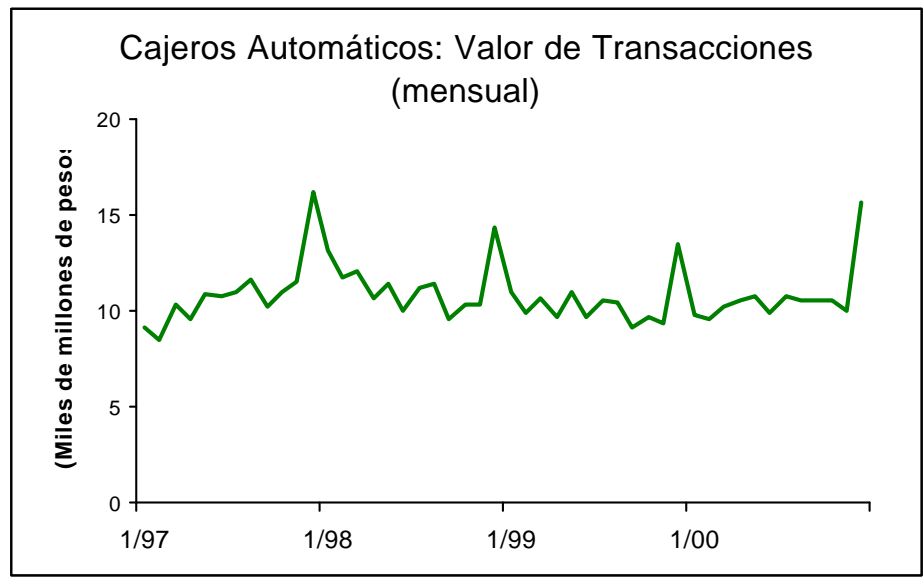

\subsection{Cheques}

La operación de los cheques en México es bastante estándar. Los bancos reciben depósitos en forma de cheques de otros bancos para posteriormente realizar la compensación en cámaras de compensación regionales. Cecoban, ${ }^{14}$ una compañía administrada por un conjunto de bancos, es responsable de la administración de las 44 cámaras de compensación distribuidas en todo el país. Cecoban concentra las operaciones de dichas cámaras y realiza la liquidación de los créditos y débitos finales a través del Sistema de Cámaras (SICAM) que opera el Banco de México. Este último, finalmente, refleja las mencionadas operaciones en las cuentas únicas que los bancos comerciales mantienen en el Instituto Central. ${ }^{15}$ Para diciembre del año 2000, las operaciones de

\footnotetext{
${ }^{14}$ El Centro de Compensación Bancaria (Cecoban) inició sus operaciones el 23 de mayo de 1980 como un fideicomiso operado y administrado por el Banco de México. El 29 de febrero de 1997 se liquidó el fideicomiso. A partir del 1 de marzo de 1997 Cecoban S.A. opera como una empresa privada administrada por los bancos comerciales.

15 El Banco de México mantiene las cuentas corrientes de los bancos comerciales y de desarrollo, de las casas de bolsa, de los fondos de pensiones y de algunas entidades del sector público. En la actualidad 98 instituciones tienen cuenta en el Banco de México (Banco de México, 2001).
} 
tres cámaras de compensación (la Ciudad de México, Monterrey y Guadalajara) representaban $50 \%$ del total de operaciones así como $59 \%$ del valor total operado en cheques. ${ }^{16}$

\section{Gráfica 3}

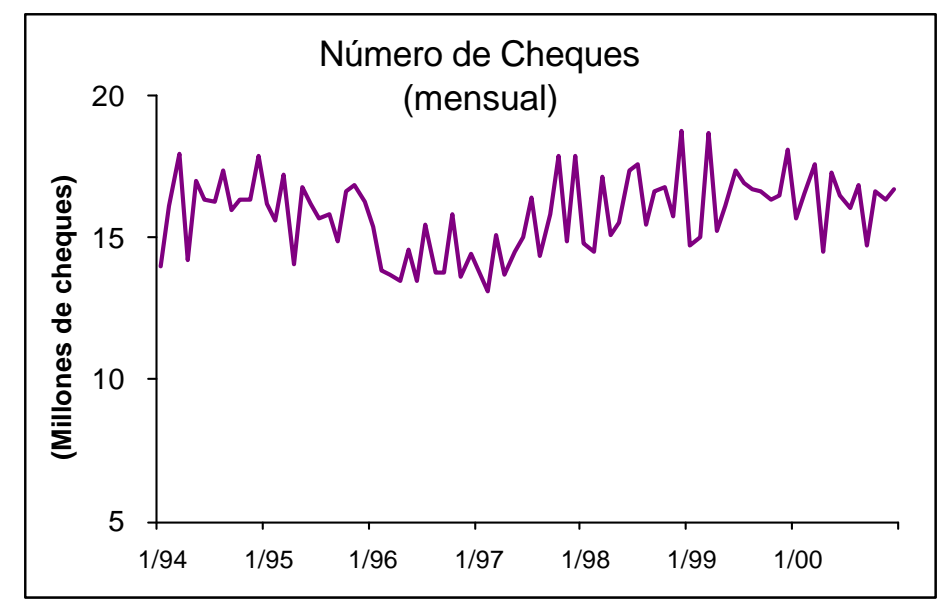

La Gráfica 3 presenta el número de cheques que fueron liquidados mensualmente de 1994 a 2000. ${ }^{17}$ Puede apreciarse que el número de cheques ha permanecido bastante estable en el período, fluctuando entre 14 y 17 millones al mes. Estas cifras reflejan un promedio diario de alrededor de 800 mil cheques liquidados.

En contraste, el valor mensual de las transacciones con cheques, expresado en pesos constantes de diciembre del 2000, ha caído de manera sustancial. La Gráfica 4 muestra que el valor mensual de los cheques liquidados inició una tendencia descendente desde 1994. La caída se hizo más marcada después de marzo de 1995, cuando los pagos electrónicos de alto valor fueron introducidos en México. ${ }^{18}$ Adicionalmente, el Banco de México adoptó medidas para promover el uso de los pagos electrónicos, dada su mayor eficiencia. Hasta antes del 4 de enero de 1996 el valor de los cheques depositados era acreditado el mismo día (tiempo T). La reforma hizo que los cheques depositados el día de hoy fueran acreditados hasta el día siguiente (tiempo $\mathrm{T}+1)$. Es decir, se encareció el uso de los cheques en relación con el de los pagos electrónicos de alto valor, los

\footnotetext{
${ }^{16}$ Estas proporciones han permanecido en ese nivel desde 1998.

${ }^{17}$ Estas cifras solamente incluyen el número de cheques compensados entre bancos. El complemento de los cheques emitidos son los cheques que fueron pagados al interior del mismo banco (lo que en inglés se conoce como "on-us") y no se incluyen porque no se tiene acceso a estas cifras. Para Canadá y los Estados Unidos el número de cheques "onus" representaba $29.5 \%$ y $21.2 \%$ respectivamente, del total de cheques emitidos. La evidencia anecdótica parece indicar que esa proporción sería más alta en México que en los Estados Unidos por el grado de concentración del mercado bancario.

${ }^{18}$ Ver los apartados de SIAC, SPEUA y SIDV.
} 
cuales son liquidados el mismo día (tiempo T). El valor de los cheques liquidados luego de enero de 1996 sufrió una caída significativa (Gráfica 4). A partir de entonces dicho valor ha permanecido estable. Eso implica que en la actualidad, la gran mayoría de los cheques se utilizan para realizar transacciones de bajo valor.

\section{Gráfica 4}

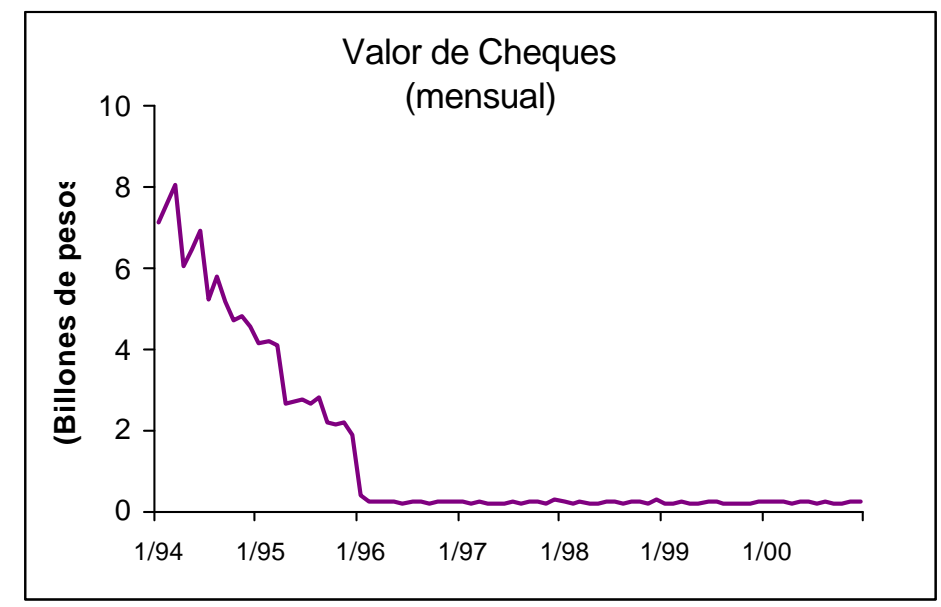

\subsection{Tarjetas de crédito}

Un porcentaje relativamente reducido de la población mexicana tiene acceso al mercado de tarjetas de crédito. ${ }^{19}$ Este mercado empezó a desarrollarse en los años sesenta, aunque las tarjetas de servicios tipo Dinners Club habían sido introducidas al mercado desde los años cincuenta. ${ }^{20}$ En México, como en todo el mundo, en una transacción pagada con tarjeta de crédito participan cuatro agentes: el tarjetahabiente que realiza el pago, el banco emisor de la tarjeta, el comercio receptor del pago y el banco del comerciante, denominado banco adquiriente. ${ }^{21}$ En general, el banco adquiriente cobra al comercio afiliado un porcentaje del valor de la transacción; el banco adquiriente, a su vez, transfiere la mayor parte de ese porcentaje al banco emisor de la tarjeta puesto que es éste último el que incurre en el riesgo de crédito. ${ }^{22}$

\footnotetext{
${ }^{19}$ Negrín y Martínez (2000) utilizan la Encuesta Nacional Ingreso Gasto de los Hogares para mostrar que en 1994, solamente el $7.8 \%$ de los hogares utilizó una tarjeta de crédito en el período de levantamiento de la encuesta. Dicha proporción disminuyó a $6.1 \%$ en la encuesta de 1996, luego de la crisis financiera.

${ }^{20}$ Ver Figueroa, 1995.

${ }^{21}$ Ver Evans y Schmalensee (1999).

${ }^{22}$ En entrevistas privadas, gerentes de bancos comerciales señalaron que para el año 2000, la comisión o tarifa que el comercio afiliado pagaba al banco adquiriente, fue de entre $4 \%$ y $4.8 \%$ del valor de la transacción. El banco adquiriente pagaba más del $80 \%$ de esa tarifa al banco emisor de la tarjeta.
} 
El mercado de tarjetas de crédito mexicano es similar al de los cajeros automáticos. Los dos bancos mayores tienen sus propios sistemas mientras que Prosa controla un tercer sistema. Los tres sistemas se apoyan entre sí y liquidan al final del día. La liquidación se realiza de manera independiente, sin participación del Banco Central. Las transacciones internacionales son controladas directamente por Visa y Mastercard, las cuales están relacionadas con los tres sistemas arriba descritos. Casi todos los bancos mexicanos emiten tarjetas de crédito y están afiliados con Visa o Mastercard o con ambos.

\section{Gráfica 5}

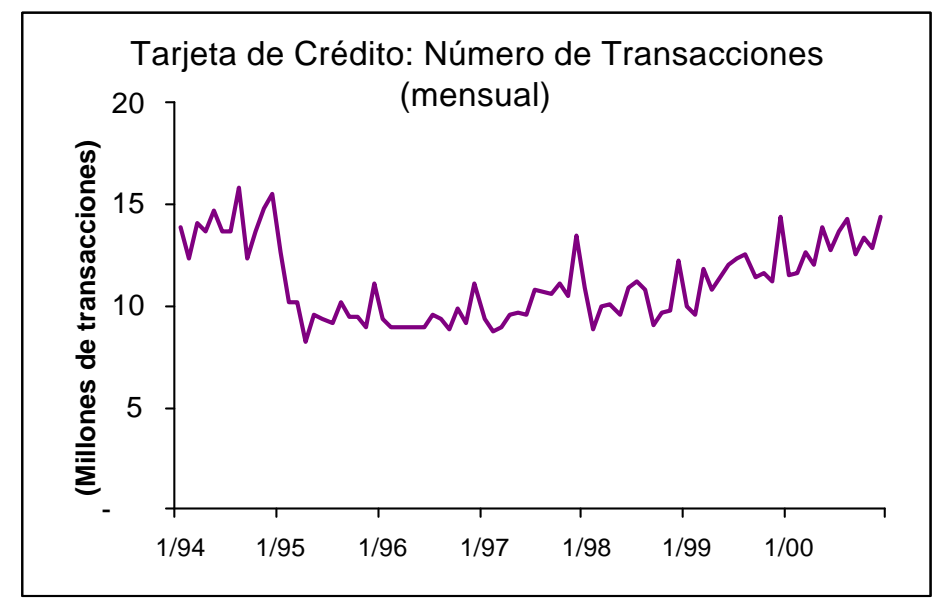

La crisis bancaria de 1994-95 propició una contracción considerable del número de tarjetas de crédito. Antes de la crisis había alrededor de 14 millones de tarjetas en el mercado. El alza en las tasas de interés y las restricciones sobre la emisión de tarjetas que resultaron del incremento en la cartera vencida y de las restricciones regulatorias, explican la reducción de aproximadamente 50\% de las tarjetas de crédito que ocurrió en los siguientes dos años. Entre los cambios regulatorios realizados, se encuentran aquéllos orientados a limitar el riesgo que los bancos estaban tomando. La regulación impidió a los bancos emitir tarjetas de crédito sin contar con una solicitud explícita firmada por el cliente con ese fin. La emisión de tarjetas sin que existiera una solicitud previa, fue una práctica común de los bancos. ${ }^{23}$ Adicionalmente, a partir de 1998 los reguladores requirieron a los bancos contar con un reporte de la historia crediticia del solicitante proporcionado por alguna sociedad de información crediticia antes de emitir una tarjeta; en caso de no hacerlo, los bancos

\footnotetext{
${ }^{23}$ Ver "Reglas a las que habrán de sujetarse las instituciones de banca múltiple en la emisión y operación de tarjetas de crédito bancarias”, Banco de México, 18 de diciembre de 1995.
} 
deberían de provisionar dichos créditos al 100\%. ${ }^{24}$ Luego del fuerte ajuste en 1995 y 1996 , el número de tarjetas de crédito se ubicó en alrededor de 7 millones de tarjetas, número que se ha mantenido estable desde entonces. Aunque la caída no fue tan pronunciada, la Gráfica 5 muestra el efecto negativo que la contracción en el número de tarjetas tuvo sobre el número de transacciones. ${ }^{25}$ La Gráfica 5 muestra también que, a partir de 1998, el número de transacciones ha registrado una recuperación lenta pero sostenida.

\section{Gráfica 6}

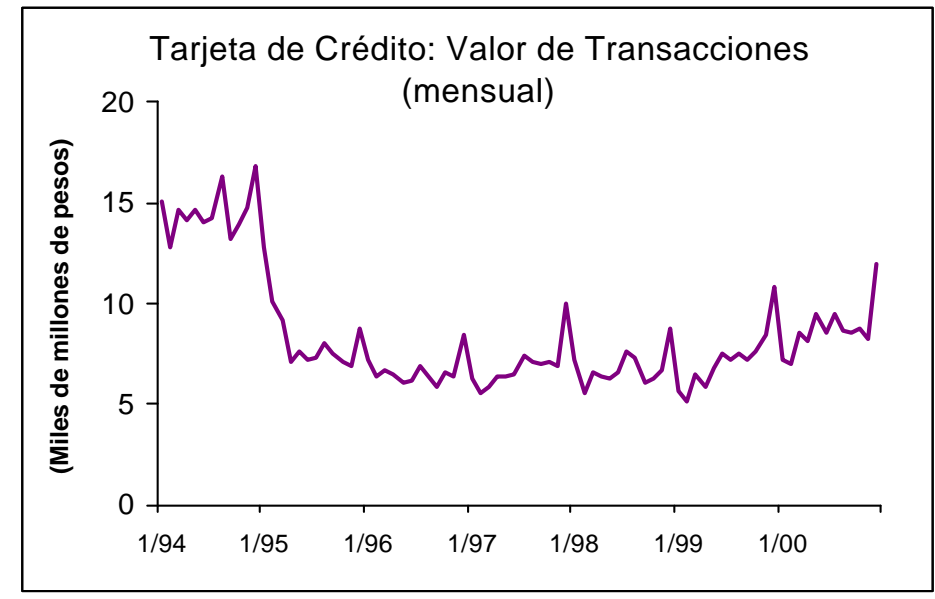

La contracción del número de tarjetas tuvo un efecto más profundo sobre el valor de las transacciones que se llevan a cabo con tarjetas de crédito, como queda ilustrado en la Gráfica 6. Dicho valor, expresado en pesos constantes de diciembre del 2000, se contrajo en $45 \%$ de diciembre de 1994 a abril de 1995. El hecho de que el valor de las transacciones haya caído más que el número de transacciones indica que el valor promedio de las transacciones se redujo. ${ }^{26}$ Luego de ello, el valor ha permanecido relativamente estable, iniciándose una recuperación a partir de 1999.

\footnotetext{
${ }^{24}$ Banco de México, Circular 75/98.

${ }^{25}$ Incluye el número de transacciones de Banamex, Bancomer y Carnet-Prosa.

${ }^{26}$ Los resultados de Negrín y Martínez (2000), indican que los segmentos de la población con ingresos más elevados fueron los que en mayor medida dejaron de utilizar sus tarjetas de crédito. Si supusiéramos que los segmentos de alto ingreso realizan las transacciones de mayor valor, esto podría explicar que la caída haya sido más pronunciada en el valor que en el número de transacciones.
} 


\subsection{Tarjetas de débito}

Las tarjetas de débito constituyen uno de los medio de pago de alto volumen de más rápido crecimiento en los últimos años en México. Desde hace varios años los bancos han emitido tarjetas de efectivo vinculadas a cuentas de cheques y de ahorros, las cuales eran utilizadas principalmente para realizar retiros de cajeros automáticos. Sin embargo, a mediados de los años noventa, los bancos empezaron a emitir tarjetas de débito; estas tarjetas, además de poder usarse como tarjetas de retiro de efectivo, tienen la capacidad de ser un medio de pago directo en más de 100 mil puntos de venta existentes en México. Esta nueva función y el creciente número de empleados que reciben sus pagos de nómina a través transferencias electrónicas para lo cual requieren cuentas bancarias, han generado un aumento en el número de tarjetas de débito de 14.1 millones en enero de 1997 a 33.3 millones en diciembre del 2000.

Gráfica 7

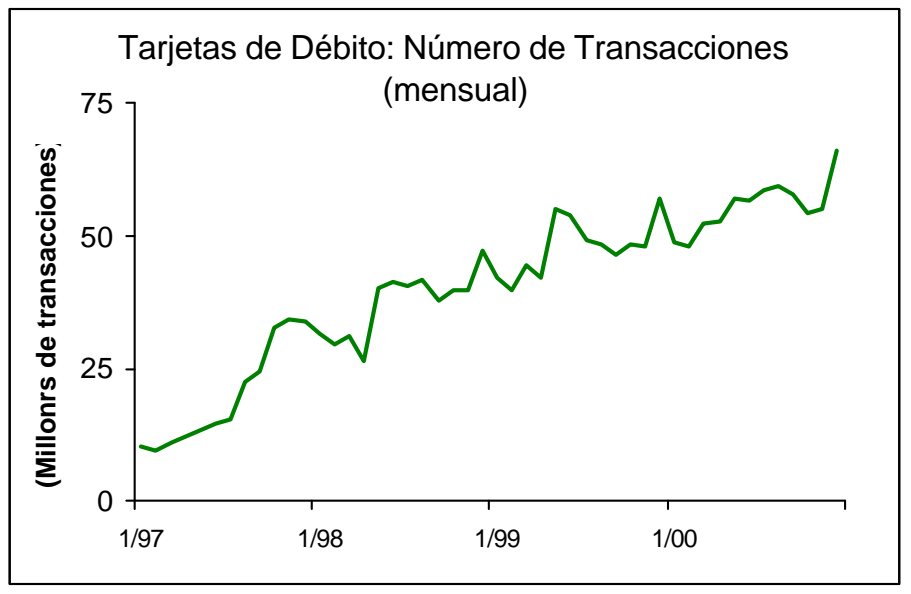

Como ocurre con los retiros de cajeros automáticos, cuando se realizan pagos con tarjetas de débito, el monto de la transacción es deducido inmediatamente de la cuenta bancaria del tarjetahabiente. Cuando las tarjetas de débito fueron introducidas, no eran aceptadas como medio de pago en puntos de venta. Esta situación cambió en 1997, cuando las tarjetas de débito empezaron a admitirse como medio de pago. Dichas transacciones se canalizan sobre la infraestructura existente para las tarjetas de crédito, lo cual ha permitido un rápido crecimiento en el mercado de tarjetas de 
débito. ${ }^{27}$ Como se aprecia en al Gráfica 7, el número de transacciones con tarjeta de débito se ha multiplicado por un factor de 5.5 de enero de 1997 a diciembre del $2000 .^{28}$

El valor de las transacciones realizadas con tarjetas de débito expresado en pesos constantes de diciembre del 2000, se presenta en la Gráfica $8 .^{29}$ Al igual que el número, el valor de las transacciones ha registrado un continuo incremento en los últimos años. De hecho, de enero de 1997 a diciembre del 2000, dicho valor se ha multiplicado por un factor de dos. Esta tendencia positiva indica que la adopción de la tecnología de tarjetas de débito se encuentra aún en expansión y no ha alcanzado una etapa madura. Es decir, es muy probable que este comportamiento se mantenga en los años venideros.

\section{Gráfica 8}

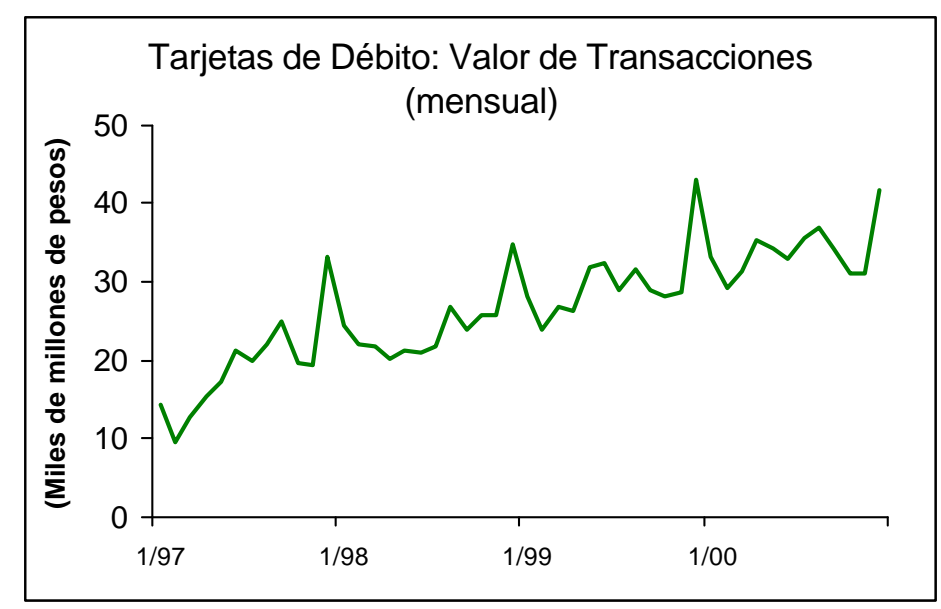

\subsection{Pago Interbancario}

Las transferencias de fondos constituyen una importante categoría entre los pagos electrónicos. ${ }^{30}$ En México el sistema de transferencias electrónicas de alto volumen es el llamado Pago Interbancario. Como ocurre en otros países, el Pago Interbancario se utiliza para realizar pagos

\footnotetext{
${ }^{27}$ En entrevistas privadas, gerentes de bancos comerciales indicaron que para el año 2000, el banco adquiriente cobraba una tarifa fija a los comerciantes receptores del pago efectuado con tarjeta de débito. La tarifa establecida por transacción fluctuaba entre 90 centavos y 1.40 pesos. El banco adquiriente sólo pagaba al banco emisor alrededor de 15 centavos por transacción.

${ }^{28}$ Incluye datos de Banamex, Bancomer y Prosa.

${ }^{29}$ Se cuenta directamente con los datos de valor de transacciones de las tarjetas de débito de Prosa y con el número total de tarjetas de débito del sistema bancario (incluyendo a Banamex, Bancomer y Prosa). Para obtener los datos para todo el sistema, se utilizó la proporción de tarjetas de débito de Prosa en el total del sistema y el valor de Prosa. El supuesto es que el valor de las transacciones de Prosa es representativo para todo el sistema.

${ }^{30}$ Ver la sección 3 para una descripción más detallada del funcionamiento de las transferencias electrónicas.
} 
periódicos de relativamente bajo valor, como los pagos de nómina y de algunos servicios. Este sistema permite realizar pagos electrónicos entre los clientes de los bancos.

El desarrollo de estos pagos en México se inició en 1996; sin embargo, el sistema pasó por un período de adopción lenta. Ciertas mejoras administrativas y legales configuraron un esquema de operación similar al de las Automated Clearing Houses (ACHs) de los Estados Unidos. La lenta adopción inicial tal vez se relaciona con el hecho de que no todos los bancos requieren de este servicio en la misma medida. De hecho, para los bancos que cuentan con un menor número de sucursales, resultan indispensables las conexiones con otros bancos para realizar transferencias electrónicas. Han sido estos bancos los principales promotores del Pago Interbancario. En contraste, los requerimientos de conexiones de los bancos que cuentan con una red nacional de sucursales, son menores. A pesar de ello, a partir de finales de 1998 el sistema se ha expandido rápidamente, como se aprecia en las Gráficas 9 y 10.

El sistema de Pago Interbancario es administrado por la misma empresa que se encarga de la compensación de cheques - Cecoban. Todos los días Cecoban efectúa la liquidación de los pagos interbancarios que ocurren en el país. La liquidación se realiza en las cuentas que los bancos tienen en el Banco de México, las cuales son administradas por el SIAC. La liquidación tiene lugar a las 10 AM del día siguiente. Por tanto, desde la perspectiva del usuario, las operaciones realizadas en este sistema se registran valor día siguiente (tiempo T+1). El Banco de México garantiza la liquidación y los pagos son finales.

\section{Gráfica 9}

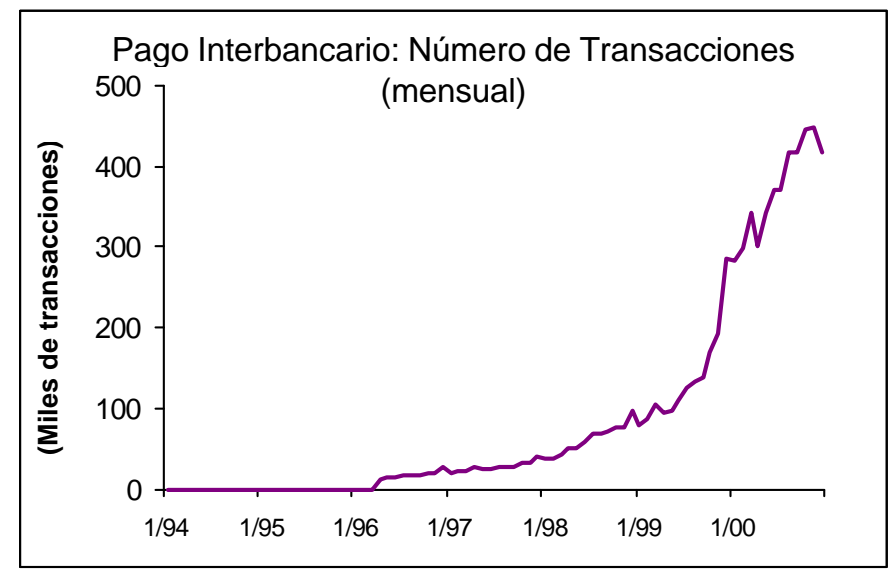

A pesar de la liquidación valor día siguiente, recientemente este medio ha registrado un crecimiento considerable. Ello obedece no sólo a la acción de los bancos que cuentan con un 
menor número de sucursales, sino también al uso del servicio que están efectuando algunas agencias gubernamentales. El impulso que estos pagos han recibido ha dado lugar a un crecimiento exponencial del número de transacciones, el cual se presenta en la Gráfica 9. De enero de 1999 a diciembre del 2000, dicho número se multiplicó por un factor de 4.2. Este rápido incremento, precedido por una baja tasa de utilización, sigue de cerca el comportamiento usual de adopción de tecnología (Rogers, 1995); es decir, el Pago Interbancario se encuentra en una fase de adopción expansiva. Por tanto, es muy probable que en el futuro inmediato continúe creciendo rápidamente. Cabe destacar que la reciente introducción de la "Banca por Internet" permite a los clientes de los bancos realizar transferencias de fondos electrónicas; estas transferencias están contribuyendo al aumento en el uso del Pago Interbancario, pues se transmiten a través de este sistema.

La Gráfica 10 presenta el valor de las transacciones que se ha canalizado a través del Pago Interbancario expresado en pesos constantes de diciembre de 2000. Como ocurrió con el número de transacciones, el valor de las mismas creció rápidamente en los últimos 3 años. De enero de 1998 a diciembre del año 2000, el valor de las transacciones canalizadas por Pago Interbancario se multiplicó por un factor de 11. Además de ese crecimiento, la gráfica muestra un marcado patrón estacional; dicho patrón se relaciona con los pagos que realizan algunas agencias gubernamentales.

\section{Gráfica 10}

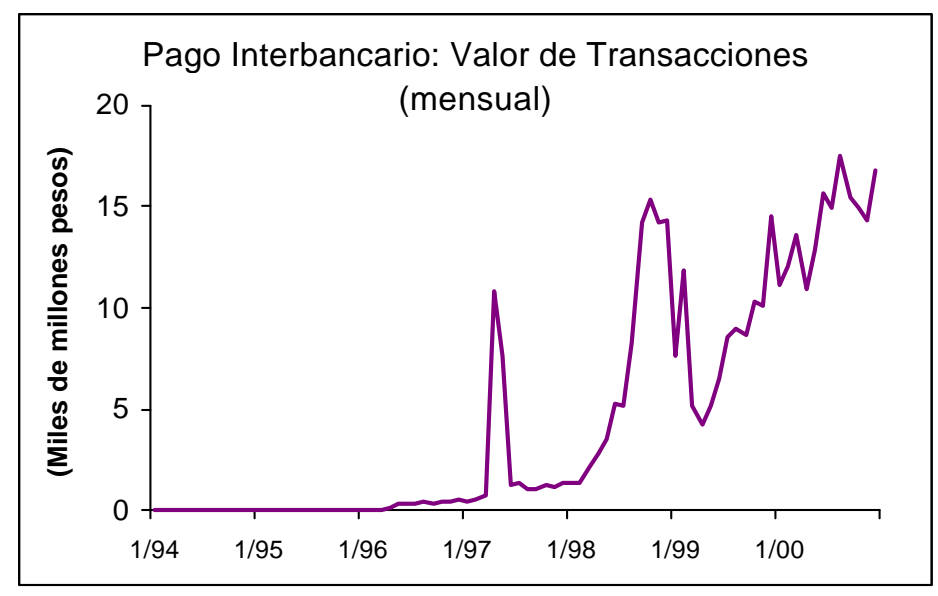

\section{Pagos de Alto Valor}

Los pagos de Alto Valor, conocidos también como de mayoreo, se utilizan principalmente para realizar transacciones entre bancos o entre bancos y casas de bolsa. Como su nombre lo indica, el 
valor de estas transacciones es muy elevado; en el caso de México el valor promedio de las transacciones es superior a los 20 millones de pesos. En México el desarrollo de las transferencias electrónicas ha tenido un efecto importante en los pagos de alto valor. Este desarrollo se debió a una reforma integral de los sistemas de pagos realizada a partir de 1994 por el Banco de México. En esta reforma se intentó simultáneamente, mejorar la eficiencia de los sistemas y reducir el riesgo sistémico. Como resultado de la reforma, existen tres sistemas de pago de alto valor, todos ellos conectados entre sí. En esta sección se describe el funcionamiento de estos sistemas así como la evolución de las transacciones que se efectúan en ellos.

\subsection{Desarrollo de los Sistemas de Pago}

En México existen tres sistemas para realizar transferencias en línea de fondos de alto valor. El primero de ellos, el Sistema de Atención a Cuentahabientes (SIAC), inició operaciones en 1991 y se utiliza principalmente para realizar transferencias de fondos entre bancos y casas de bolsa. El segundo, el Sistema de Pagos Electrónicos de Uso Ampliado (SPEUA), empezó a operar en 1995 y su función es la transferencia de fondos de alto valor entre empresas e individuos por medio de intermediarios bancarios. Finalmente, el Sistema de Información de Depósito de Valores (SIDV) inició operaciones en 1997 y es utilizado por bancos y casas de bolsa para realizar transacciones de bonos públicos, acciones y valores. Los dos primeros sistemas son administrados por el Banco de México, mientras que el SIDV es manejado por el Instituto para el Depósito de Valores (INDEVAL). Tanto el SIDV como el SPEUA efectúan la liquidación final en el SIAC.

Los bancos comerciales mexicanos mantienen una cuenta de reserva con el banco central conocida como cuenta única. Aunque los requerimientos de reserva han sido eliminados en México, ${ }^{31}$ esta cuenta ha funcionado también como el mecanismo para liquidar transacciones interbancarias tales como transferencias de fondos, liquidación de operaciones en las cámaras de compensación y liquidación de transacciones en divisas y en valores. Antes de 1991, todas las transacciones entre bancos que se realizaban en las cuentas únicas eran manejadas por medio de operaciones en papel. ${ }^{32}$ Supóngase, por ejemplo, que el banco A compraba al banco B un millón de pesos en bonos gubernamentales. El banco A enviaba al Banco de México una forma (similar a un cheque) solicitando que se transfiriera un millón de pesos de su cuenta única y se acreditara en

\footnotetext{
${ }^{31}$ Schwartz (1998) provee una descripción histórica reciente de los requerimientos de reserva en México.

${ }^{32}$ Las operaciones interbancarias se manejan "fuera de bolsa” (en inglés, “over the counter”).
} 
la cuenta única del banco B. El banco B por su parte, enviaba otra forma solicitando que se transfiriera un millón de pesos en bonos gubernamentales de su cuenta única a la del banco A. Este mismo proceso se realizaba para todas las transacciones que tenían lugar durante el día. Al final del día, el sistema de cómputo del Banco de México procesaba todas las formas de papel, liquidaba las cuentas y generaba un estado de cuenta para cada banco, el cual era enviado al día siguiente por mensajería a los bancos correspondientes. ${ }^{33}$ Este proceso significaba que aún en el caso de sobregiros intra-día y nocturnos, el Banco de México garantizaba todos los pagos incurriendo en un riesgo de liquidación excesivo. ${ }^{34}$

Con el propósito de hacer más eficientes las operaciones efectuadas por los bancos comerciales con el Banco Central, en 1991 el Banco de México introdujo la primera versión del SIAC. Este sistema permitía la realización de transferencias electrónicas en línea entre los bancos comerciales, casas de bolsa y algunas oficinas de gobierno a las cuentas de sus contrapartes. ${ }^{35}$ En contraste con la liquidación al final del día del sistema basado en papel, el SIAC liquidaba en tiempo real y todas las transacciones eran finales. Sin embargo, puesto que "el Banco de México garantizaba todos los pagos y permitía sobregiros intra-día en pesos, gratuitos, ilimitados y sin garantía" (Chakravorti, 1997, p16), la introducción del SIAC dio lugar a sobregiros intra-día. Los sobregiros eran generados por la liquidación inmediata de operaciones apoyada en los recursos del Banco de México. En otras palabras, el Banco de México seguía asumiendo un excesivo riesgo de liquidación.

En estas condiciones, en 1994 se inició una reforma integral de los sistemas de pago en México. La reforma intentaba, por un lado, reducir la exposición del Banco de México al riesgo y, por otro, establecer un balance apropiado entre la eficiencia y la seguridad del sistema. La reforma siguió varios criterios, entre ellos, lograr una distribución equitativa del riesgo entre los participantes en el sistema, limitar los sobregiros intra-día, impulsar el tránsito de los pagos de alto valor de un sistema basado en papel a otro fundado en transferencias electrónicas y desarrollar un sistema de pagos específico para valores en un ambiente de entrega contra pago (Sánchez-Arroyo, 1996). De

\footnotetext{
${ }^{33}$ El sistema del banco central que procesaba todas las operaciones interbancarias antes de 1991 se llamaba Sistema de Información Contable (SIC). Este sistema fue el que precedió al SIAC.

${ }^{34}$ Ver nota 4 para la definición de riesgo de liquidación. Para una discusión acerca de los sobregiros intra-día y el riesgo sistémico, ver Belton (1987) y Vanhoose y Gordon (1989).

${ }^{35}$ Ver Jallath (2000) para una explicación detallada de los efectos de la implantación del SIAC en el sistema financiero mexicano.
} 
esta manera, la reforma no sólo incluyó al SIAC, sino que introdujo dos nuevos sistemas de pago, el SPEUA y el SIDV. Los dos nuevos sistemas están ligados a través del SIAC, de modo que un participante puede transferir fondos de un sistema para cumplir con sus obligaciones en otro.

La reforma del sistema de pagos sin duda ha distribuido mejor el riesgo y ha elevado la eficiencia de los pagos. Aunque el Banco de México aún carga con una parte importante del riesgo en razón de garantizar la liquidez del sistema, existe una mejor distribución del mismo entre los participantes. Esto induce a que los participantes tiendan a autoregularse. En los siguientes apartados se detallan los efectos de la reforma sobre cada uno de los sistemas de pago.

\subsection{SIAC}

Por lo que se refiere al SIAC, los participantes siguieron siendo las instituciones que tienen una cuenta con el Banco de México. Sin embargo, la reforma sustituyó las transacciones intra-día sin garantía por sobregiros totalmente colateralizados. En la actualidad una de las principales funciones del SIAC es que otros sistemas de pago, como el SPEUA, el SIDV, el Pago Interbancario y el SICAM, liquiden en él. Dado que la reforma dio lugar a la creación de otros sistemas de pago, el número de transacciones que se realizan a través del SIAC ha sufrido una continua reducción de 1995 a 2000. Esta evolución está representada en la Gráfica 11. Sin embargo, el valor de las transacciones que se efectúan en el SIAC, expresado en pesos constantes de diciembre del 2000, luego de una caída en 1995, ha permanecido relativamente estable, como lo ilustra la Gráfica 12.

\subsection{SPEUA}

El SPEUA, implantado en 1995, es un sistema de alto valor en tiempo real de liquidación bruta ${ }^{36}$ que funciona de manera paralela al SIAC. El sistema se creó con la intención de sustituir los cheques de alto valor por transferencias electrónicas. Esto aumentaba la eficiencia del sistema y reducía el riesgo en que incurría el Banco de México; de este modo, el sistema se orienta a la transferencia de fondos entre los bancos y sus clientes. En su diseño el SPEUA incluye una facilidad de crédito multilateral así como un mecanismo para compartir pérdidas (Chakravorti,

\footnotetext{
${ }^{36}$ En los sistemas de liquidación bruta en tiempo real, las instituciones realizan la liquidación de cada transacción individual conforme éstas van ocurriendo. En contraste con los sistemas brutos, se encuentran los esquemas de liquidación neta, en los cuales la liquidación se realiza al final del día y solamente se transfiere el valor neto de las operaciones que realiza cada institución.
} 
1997). Por medio de la facilidad de crédito multilateral, los participantes se otorgan crédito entre sí y ellos mismos determinan los montos de crédito que se conceden. Esta facilidad funciona de la manera siguiente. Cierto banco A provee de crédito a otro banco cualquiera llamado B; de manera recíproca, B le concede crédito al banco A. Este arreglo bilateral, al repetirse entre todos los participantes, se convierte en un acuerdo de crédito multilateral. Cada día todos los bancos definen los límites de crédito que le conceden a otros bancos, lo cual determina la exposición total al riesgo de cada banco. Las líneas de crédito recíprocas permiten un flujo de pagos continuo y sin sobresaltos en el sistema. ${ }^{37}$ A las 6 P.M. todos los créditos y débitos generados en el SPEUA son liquidados en las cuentas únicas que los bancos tienen en el SIAC. Si al final del día algún participante no puede cumplir con sus obligaciones de pago, el Banco de México le provee el crédito necesario sin garantías y cobra una multa al banco incumplido. Si el participante en problemas falta a sus obligaciones definitivamente, el arreglo de pérdidas compartidas distribuye los costos de la deuda entre todos aquellos bancos que le hubiesen proporcionado crédito al participante que falló. Este mecanismo provee incentivos para que el sistema se autoregule.

Para inducir a las empresas e individuos a sustituir los cheques de alto valor por transferencias electrónicas del SPEUA, el 4 de enero de 1996 el Banco de México modificó el tiempo de liquidación de cheques de valor mismo día (tiempo T) a valor día siguiente (tiempo T+1). La Gráfica 11 presenta el enorme cambio que ocurrió en el número de transacciones del SPEUA luego de que esta medida fue adoptada: las transacciones por el SPEUA se elevaron sustancialmente, luego de lo cual se han mantenido en crecimiento.

Las sucesivas reducciones en el valor mínimo de la transferencia contribuyen a explicar el aumento continuo en el uso del SPEUA. En principio, se fijó un valor elevado a la transferencia mínima para limitar el número de pagos - 500,000 pesos- pues los bancos comerciales no contaban con la infraestructura suficiente para satisfacer una demanda elevada. ${ }^{38}$ Sin embargo, conforme la infraestructura de los bancos ha ido mejorando, el valor mínimo de la transferencia se ha reducido. En diciembre de 1995 el mínimo se fijó en 150 mil pesos; en junio de 1996 dicho valor se redujo a 100 mil pesos. En abril de 1997 ocurrió una nueva reducción del valor mínimo a 80 mil pesos y,

\footnotetext{
${ }^{37}$ El Banco de México estableció que la exposición total al riesgo de cada banco estuviera limitada por la siguiente fórmula: $\mathrm{L}+0.824361 * \mathrm{~L} * \mathrm{EXP}\left(-0.0000001252 * \mathrm{~L}^{2}\right)$, donde $\mathrm{L}=\mathrm{MAX}(1.5 *$ capital, $0.12 *$ pasivos) (Ver, Banco de México, Circular 2019/95)

${ }^{38}$ En Septiembre de 1995, 500,000 pesos equivalían a 73,000 dólares americanos.
} 
finalmente, en agosto de 1997, dicho límite se fijó en 50 mil pesos, mismo que ha permanecido vigente hasta la fecha. ${ }^{39}$

Gráfica 11

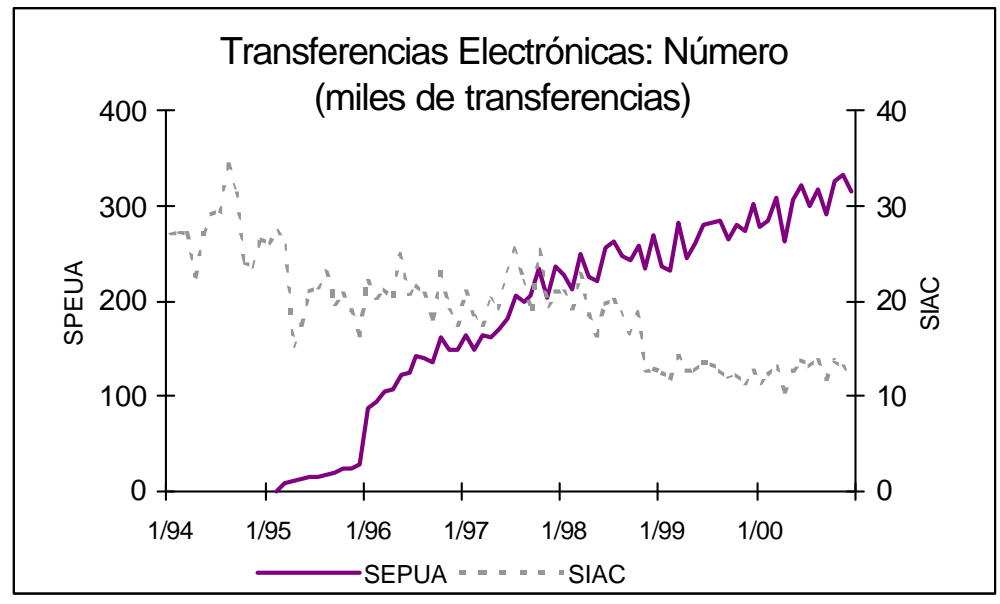

El efecto de la reducción en el valor mínimo de la transferencia puede observarse en la Gráfica 11, donde se percibe que el número de transferencias por medio del SPEUA ha continuado en ascenso desde el momento de su introducción hasta la fecha. Sin embargo, la Gráfica 12 muestra que el valor de las transferencias que se canalizan por el SPEUA, expresado en pesos constantes de diciembre del año 2000, ha registrado un cierto estancamiento desde 1998. Esto significa que el valor promedio de la transacción por el SPEUA ha tendido a caer; esto indica que mientras aquellos usuarios grandes ya han adoptado por completo la tecnología del SPEUA, solamente usuarios menores están adoptándola ahora. Es decir, este sistema parece aproximarse a la etapa madura de adopción de tecnología.

\subsection{SIDV}

El tercer sistema, el SIDV, es utilizado exclusivamente para efectuar pagos de transacciones de títulos de deuda bancaria, de deuda gubernamental y de acciones. En este sistema, administrado por el INDEVAL, ${ }^{40}$ participan bancos y casas de bolsa. Dada su naturaleza, las transacciones que se transmiten son pocas y de muy alto valor. Para reducir el riesgo, la reforma estableció que este

\footnotetext{
${ }^{39}$ Conviene destacar que dichos valores fueron establecidos en precios nominales, por lo que la contracción en términos reales ha sido aún mayor. De esta forma, mientras que en agosto de 199750 mil pesos equivalían a 6 mil 400 dólares, en diciembre de 2000 solamente equivalían a 5 mil 200 dólares.

${ }^{40}$ El INDEVAL S.A. de C.V. empresa privada. El Banco de México es el depositario de los títulos gubernamentales; sin embargo ha acordado con el INDEVAL que sea esta empresa la que administre las operaciones con títulos del gobierno.
} 
sistema siguiera el modelo de entrega contra pago. Cada participante en el sistema tiene dos cuentas una de valores y otra de control de fondos (efectivo). Para los valores el sistema liquida a lo largo del día (liquidación bruta), mientras que para efectivo la liquidación es al final del día (liquidación neta). Cuando una transacción se lleva a cabo en el esquema de entrega contra pago, ${ }^{41}$ el vendedor debe tener los valores en su cuenta de valores y el comprador debe de tener un saldo positivo en su cuenta de efectivo; además de esos fondos, el comprador puede contar con capacidad de retiro de fondos, ya sea una línea de crédito totalmente colateralizada con valores gubernamentales o una línea de crédito proporcionada por los bancos, para transacciones en el SIDV. La capacidad de retiro del comprador es la que sea menor entre esas dos líneas de crédito. La línea de crédito que canalizan los bancos a los usuarios del SIDV, esta constituida con recursos que el Banco de México les concede para asegurar la liquidez del sistema. Todos los días el Banco de México proporciona crédito a los bancos para transacciones en el SIDV; dichas líneas representan alrededor de $60 \%$ del crédito agregado del SPEUA. Los bancos, a su vez, distribuyen esas líneas de crédito entre los participantes en el SIDV. Además de sus cuentas de efectivo y de las líneas de crédito, los compradores pueden transferir fondos del SPEUA o del SIAC para pagar sus transacciones (Chakravorti, 1997). En caso de que alguna casa de bolsa tenga un débito al final del día, el sistema efectúa operaciones de reporto para transferir los valores de la casa de bolsa en problemas hacia los bancos que le dieron crédito. El efectivo de los reportos se deposita en la cuenta de efectivo de la casa de bolsa en cuestión. Las cuentas de control de efectivo de los bancos están relacionadas con la cuenta que cada banco mantiene en el SIAC. Si un banco no tiene suficiente crédito en el SIAC, el Banco de México acepta el sobregiro y toma en garantía los valores del banco. Con este sistema de crédito, en el momento en que las operaciones son procesadas por el SIDV, son finales (Banco de México, 2001).

Como se aprecia en la Gráfica 12, de enero de 1997 a diciembre de 2000, el valor de las transacciones que se llevan a cabo a través del SIDV se ha mantenido relativamente estable. Sin embargo, dada la naturaleza de las transacciones, el SIDV es el sistema que involucra mayor valor.

\footnotetext{
41 A la "entrega contra pago" se le conoce en inglés como "delivery versus payment" (DVP). Existen 3 modelos alternativos de DVP. En el modelo 1, tanto la cuenta de valores como la de fondos liquidan de manera bruta, en el momento en que ocurren las transacciones. En el modelo 2, la cuenta de valores liquida de manera bruta y la de efectivo de manera neta (al final del día). En el modelo 3 ambas cuentas liquidan de manera neta. En el caso de México se decidió adoptar el modelo 2, que aunque implica un mayor riesgo de liquidación que el modelo 1, requiere un menor monto de fondos, por lo que resulta más barato para los participantes (Chakravorti, 1997).
} 
En la sección siguiente se observa que el SIDV representa alrededor de $60 \%$ del valor total de los medios de pago al mayoreo en México.

Gráfica 12

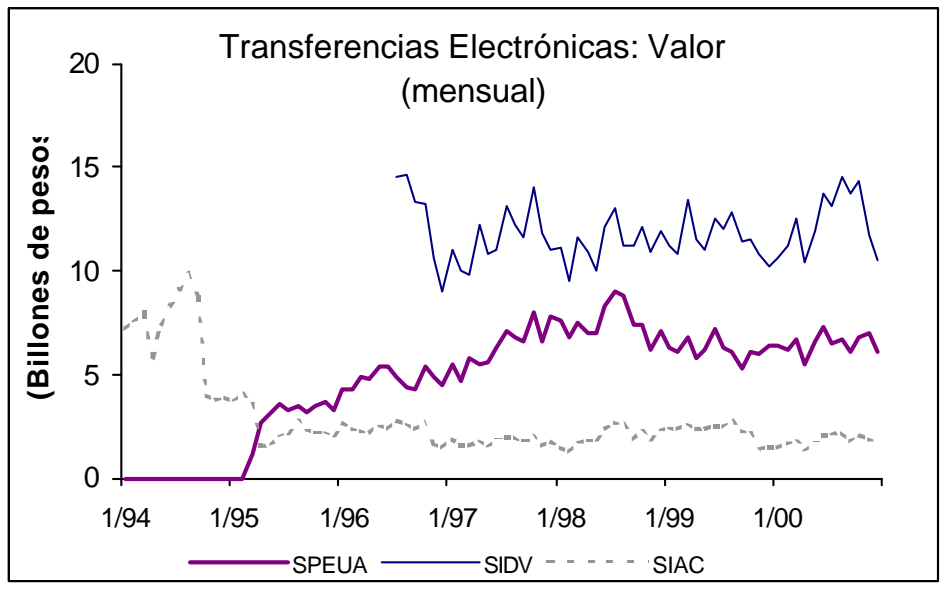

\section{La Estructura de los Pagos Distintos al Efectivo en México}

La evolución de los mecanismos individuales que fueron presentados en las secciones anteriores, ha conformado cierta estructura de pagos distintos al efectivo. En esta sección se presenta esta estructura. Aunque como ya se ha indicado, dicha estructura deja fuera algunos medios de pago, incluye sin lugar a dudas, los medios distintos al efectivo más relevantes tanto en número de transacciones como en valor. Para conformar la estructura, es conveniente mantener la separación entre los medios de pago de alto volumen y los de alto valor. Los primeros, presentados en el Cuadro 2, incluyen cheques, tarjetas de crédito, tarjetas de débito y Pago Interbancario. Los de alto valor, presentados en el Cuadro 3, incluyen el SIAC, el SPEUA y el SIDV. La estructura se presenta tanto al nivel de número de transacciones como de valor; en el caso de valor, todas las cifras están expresadas en pesos constantes de diciembre de 2000. Tanto las cifras de número de transacciones como las de valor son agregados anuales de los datos mensuales que se presentaron en las secciones anteriores. Es necesario aclarar que los medios de pago incluidos en cada grupo no necesariamente son sustitutos entre sí. Es decir, algunos medios de pago están diseñados para propósitos específicos por lo que poseen características diferenciadas; por ejemplo, el SIDV sirve exclusivamente para realizar transacciones de valores. Por tanto, las posibilidades de sustitución entre medios de pago son limitadas. Es obvio que existen mayores posibilidades de sustitución entre los medios de pago al menudeo; sin embargo, aun entre ellos, las posibilidades de sustitución no son amplias. Finalmente, en los Cuadros 4 y 5 se presenta una comparación de la estructura de 
los pagos distintos a efectivo en México con la existente en los Estados Unidos y Canadá, tanto en número de transacciones como en valor.

\subsection{Estructura de los Sistemas de Alto Volumen}

La parte superior del Cuadro 2 presenta la estructura de los medios de pago de alto volumen en términos del número de transacciones. En ese cuadro pueden destacarse varios puntos:

Cuadro 2

Estructura de Pagos de Alto Volumen en México

\begin{tabular}{|c|c|c|c|c|c|c|c|}
\hline & & Año & Cheques & $\begin{array}{c}\text { Pago } \\
\text { Inter- } \\
\text { bancario }\end{array}$ & $\begin{array}{c}\text { Tarjetas } \\
\text { de Crédito }\end{array}$ & $\begin{array}{c}\text { Tarjetas } \\
\text { de } \\
\text { Débito }\end{array}$ & Total \\
\hline \multirow{10}{*}{$\begin{array}{c}\text { Número de } \\
\text { Transacciones }\end{array}$} & \multirow{5}{*}{$\begin{array}{c}\text { Millones de } \\
\text { Transacciones }\end{array}$} & 1997 & 182.46 & 0.33 & 122.78 & 234.11 & 539.68 \\
\hline & & 1998 & 195.68 & 0.74 & 123.10 & 446.41 & 765.94 \\
\hline & & 1999 & 198.50 & 1.62 & 139.24 & 573.84 & 913.21 \\
\hline & & 2000 & 195.69 & 4.46 & 155.17 & 666.65 & $1,021.96$ \\
\hline & & Crecimiento Anual (\%) & 2.36 & 137.63 & 8.12 & 41.74 & 23.72 \\
\hline & \multirow{5}{*}{$\begin{array}{c}\text { Paricipación de } \\
\text { Mercado (\%) }\end{array}$} & 1997 & 33.81 & 0.06 & 22.75 & 43.38 & 100.00 \\
\hline & & 1998 & 25.55 & 0.10 & 16.07 & 58.28 & 100.00 \\
\hline & & 1999 & 21.74 & 0.18 & 15.25 & 62.84 & 100.00 \\
\hline & & 2000 & 19.15 & 0.44 & 15.18 & 65.23 & 100.00 \\
\hline & & Crecimiento Anual (\%) & -17.26 & 92.07 & -12.61 & 14.57 & \\
\hline \multirow{10}{*}{$\begin{array}{c}\text { Valor de } \\
\text { Transacciones }\end{array}$} & \multirow{5}{*}{$\begin{array}{c}\text { Miles de } \\
\text { Millones de } \\
\text { Pesos }^{*}\end{array}$} & 1997 & $2,797.99$ & 28.79 & 82.59 & 229.98 & $3,139.35$ \\
\hline & & 1998 & $2,782.51$ & 88.09 & 81.19 & 289.37 & $3,241.16$ \\
\hline & & 1999 & $2,688.17$ & 101.77 & 86.29 & 359.09 & $3,235.31$ \\
\hline & & 2000 & $2,723.83$ & 170.30 & 104.47 & 406.86 & $3,405.47$ \\
\hline & & Crecimiento Anual (\%) & -0.89 & 80.85 & 8.15 & 20.95 & 2.75 \\
\hline & \multirow{5}{*}{$\begin{array}{l}\text { Paricipación de } \\
\text { Mercado (\%) }\end{array}$} & 1997 & 89.13 & 0.92 & 2.63 & 7.33 & $\overline{100.00}$ \\
\hline & & 1998 & 85.85 & 2.72 & 2.50 & 8.93 & 100.00 \\
\hline & & 1999 & 83.09 & 3.15 & 2.67 & 11.10 & 100.00 \\
\hline & & 2000 & 79.98 & 5.00 & 3.07 & 11.95 & 100.00 \\
\hline & & Crecimiento Anual (\%) & -3.54 & 76.01 & 5.26 & 17.71 & \\
\hline
\end{tabular}

${ }^{*}$ Cifras en pesos de diciembre de 2000.

Fuente: Banco de Mexico y Prosa.

- El número total de transacciones de alto volumen aumentó persistentemente en los últimos cuatro años; de hecho, de 1997 a 2000, el número de transacciones registró un incremento promedio anual de $23.7 \%$.

- A pesar de que el número de cheques permaneció relativamente estable, su participación en el número total de las transacciones de alto volumen se redujo de $33.7 \%$ en 1997 a $19.1 \%$ en 2000 .

- El número de transacciones con tarjeta de débito creció a una tasa promedio anual de $41.7 \%$ de 1997 a 2000. De este modo, su participación en el total de transacciones de alto volumen aumentó de $43.4 \%$ a $65.2 \%$ en ese lapso. 
- Los Pagos Interbancarios registraron una tasa de incremento promedio anual de 137.6\%. Sin embargo, su contribución al número total de transacciones es aún reducida.

La sección inferior del Cuadro 2 muestra que a pesar del continuo ascenso del número de transacciones de alto volumen, el valor total de dichas transacciones permaneció relativamente estable de 1997 a 2000. Una vez más, es importante destacar varios elementos:

- Al igual que con el número de transacciones, la contribución de los cheques al valor total de las transacciones de alto volumen se redujo significativamente de 1997 a 2000 . A pesar de dicha reducción, durante el año 2000 los cheques continuaron representando $80 \%$ del valor total.

- Los pagos interbancarios y las tarjetas de débito experimentaron una elevación de su participación en el total del valor de las transacciones de alto volumen. Los primeros representaban solamente $0.9 \%$ del total en 1997, alcanzando 5\% en 2000. Del mismo modo, el valor de las transacciones con tarjeta de débito pasó de $7.3 \%$ a 11.9\% en el mismo lapso.

- El porcentaje que las tarjetas de crédito representan en el valor total también aumentó en el período pero a una tasa modesta.

En suma, la información anterior indica que en lo que se refiere a transacciones de alto volumen, los medios de pago más tradicionales, como los cheques y las tarjetas de crédito, están perdiendo terreno frente a los medios electrónicos menos tradicionales, como las tarjetas de débito y los Pagos Interbancarios.

\subsection{Estructura de los Sistemas de Alto Valor.}

El Cuadro 3 presenta la estructura de los medios de pago de alto valor. ${ }^{42}$ La parte superior de ese cuadro presenta dicha estructura en términos del número de transacciones. Los siguientes elementos destacan en ese cuadro:

- El número total de transacciones se elevó a una tasa promedio anual de 14.6\% de 1997 a 2000.

\footnotetext{
${ }^{42}$ El número de transacciones realizadas en el SIDV no está disponible.
} 
- El factor que explicó tal evolución fue la rápida tasa de crecimiento del SPEUA en el período $17 \%$ promedio anual; en consecuencia, el SPEUA elevó su importancia en las transacciones totales de $90 \%$ en 1997 a $96 \%$ en el año 2000.

- En contraste, el número de transacciones que se canalizaron a través del SIAC registró una tasa de crecimiento negativa, $-15.7 \%$ en promedio anual, en el período. Esta evolución redundó en una reducción en su contribución al número de transacciones totales de $10 \%$ a 4\%, de 1997 a 2000.

\section{Cuadro 3}

Estructura de Pagos de Alto Valor en México

\begin{tabular}{|c|c|c|c|c|c|c|}
\hline & & Año & SPEUA & SIAC & SIDV & Total \\
\hline \multirow{10}{*}{$\begin{array}{c}\text { Número de } \\
\text { Transacciones }\end{array}$} & \multirow{5}{*}{$\begin{array}{c}\text { Millones de } \\
\text { Transacciones }\end{array}$} & 1997 & 2.27 & 0.25 & n.d. & 2.53 \\
\hline & & 1998 & 2.90 & 0.22 & n.d. & 3.12 \\
\hline & & 1999 & 3.22 & 0.15 & n.d. & 3.37 \\
\hline & & 2000 & 3.65 & 0.15 & n.d. & 3.80 \\
\hline & & Crecimiento Anual (\%) & 17.05 & -15.71 & n.d. & 14.56 \\
\hline & \multirow{5}{*}{$\begin{array}{l}\text { Paricipación de } \\
\text { Mercado (\%) }\end{array}$} & 1997 & 90.04 & 9.96 & n.d. & 100.00 \\
\hline & & 1998 & 93.04 & 6.96 & n.d. & 100.00 \\
\hline & & 1999 & 95.50 & 4.50 & n.d. & 100.00 \\
\hline & & 2000 & 96.03 & 3.97 & n.d. & 100.00 \\
\hline & & Crecimiento Anual (\%) & 2.17 & -26.42 & n.d. & \\
\hline \multirow{10}{*}{$\begin{array}{c}\text { Valor de } \\
\text { Transacciones }\end{array}$} & \multirow{5}{*}{$\begin{array}{l}\text { Miles de } \\
\text { Millones de } \\
\text { Pesos* }\end{array}$} & 1997 & 76,226 & 21,293 & 149,204 & 246,723 \\
\hline & & 1998 & 90,130 & 24,304 & 146,353 & 260,787 \\
\hline & & 1999 & 74,410 & 27,354 & 151,175 & 252,939 \\
\hline & & 2000 & 77,684 & 21,785 & 161,628 & 261,097 \\
\hline & & Crecimiento Anual (\%) & 0.63 & 0.76 & 2.70 & 1.91 \\
\hline & \multirow{5}{*}{$\begin{array}{l}\text { Paricipación de } \\
\text { Mercado (\%) }\end{array}$} & 1997 & 30.90 & 8.63 & 60.47 & 100.00 \\
\hline & & 1998 & 34.56 & 9.32 & 56.12 & 100.00 \\
\hline & & 1999 & 29.42 & 10.81 & 59.77 & 100.00 \\
\hline & & 2000 & 29.75 & 8.34 & 61.90 & 100.00 \\
\hline & & Crecimiento Anual (\%) & -1.25 & -1.12 & 0.78 & \\
\hline
\end{tabular}

* Cifras en pesos de diciembre de 2000.

Fuente: Banco de Mexico e INDEVAL.

La parte inferior del Cuadro 3 presenta la estructura en términos de valor de las transacciones de alto valor, expresadas en pesos constantes de diciembre del año 2000. Los elementos más importantes del cuadro son los siguientes:

- Como ocurrió con el valor de las transacciones de alto volumen, el valor monetario de las transacciones de alto valor registró un modesto crecimiento, de 1.9\% promedio anual de 1997 a 2000. 
- Dicho crecimiento fue explicado en su mayor parte por el incremento en el SIDV (2.7\% promedio anual en el período) pues el incremento del SIAC y del SPEUA fue menor que $1 \%$ en promedio anual.

- Es importante destacar que la estructura en valor de los pagos de alto valor permaneció bastante estable durante el período de análisis. El SIDV representó alrededor de 60\%, el SPEUA $30 \%$ y el SIAC $10 \%$.

\subsection{Comparación Internacional}

La comparación internacional que se efectúa en esta sección proporciona una idea más completa de las peculiaridades de la estructura de los sistemas de pagos distintos al efectivo que funcionan en la economía mexicana. Los Cuadros 4 y 5 presentan una comparación, en términos de número y valor de las transacciones de los medios de pago de Canadá, los Estados Unidos y México para 1999. Dado que las economías son de dimensiones muy distintas, los datos en los cuadros se normalizan tanto por el tamaño de la población como por el valor del Producto Interno Bruto (PIB) respectivo. Existen múltiples diferencias institucionales en los medios de pago que funcionan en cada país; en esta sección se obviaron esas diferencias. Conviene señalar que no están incluidos todos los sistemas de pagos existentes en cada una de estas economías, sino los que por similitudes funcionales permiten una comparación más apropiada.

\section{Cuadro 4}

Número de Transacciones sin Efectivo en Norteamérica

(Cifras para 1999)

\begin{tabular}{|c|c|c|c|c|c|c|c|}
\hline & & Cheques $^{1}$ & P..$^{2}$ & $\begin{array}{c}\text { Alto } \\
\text { Valor }^{3}\end{array}$ & $\begin{array}{l}\text { T. de } \\
\text { Crédito }\end{array}$ & $\begin{array}{l}\text { T. de } \\
\text { Débito }\end{array}$ & Total \\
\hline \multirow{4}{*}{ México } & Millones de Transacciones & 198.5 & 1.6 & 3.4 & 139.2 & 573.8 & 916.6 \\
\hline & Estructura (\%) & 21.7 & 0.2 & 0.4 & 15.19 & 62.61 & 100.0 \\
\hline & Transacciones per cápita & 2.0 & 0.017 & 0.0 & 1.43 & 5.89 & 9.4 \\
\hline & Transacciones/PIB* & 0.4 & 0.003 & 0.0 & 0.30 & 1.23 & 2.0 \\
\hline \multirow{4}{*}{ EUA } & Millones de Transacciones & $47,891.7$ & $4,684.6$ & 160.1 & $18,827.8$ & $7,505.8$ & $79,070.0$ \\
\hline & Estructura (\%) & 60.6 & 5.9 & 0.2 & 23.81 & 9.49 & 100.0 \\
\hline & Transacciones per cápita & 175.4 & 17.2 & 0.6 & 68.94 & 27.48 & 289.5 \\
\hline & Transacciones/PIB ${ }^{\star}$ & 5.2 & 0.5 & 0.0 & 2.02 & 0.81 & 8.5 \\
\hline \multirow{4}{*}{ Canadá } & Millones de Transacciones & $1,411.4$ & 823.0 & 3.0 & $1,147.6$ & $1,661.4$ & $5,046.4$ \\
\hline & Estructura (\%) & 28.0 & 16.3 & 0.1 & 22.74 & 32.92 & 100.0 \\
\hline & Transacciones per cápita & 46.3 & 27.0 & 0.1 & 37.63 & 54.47 & 165.5 \\
\hline & Transacciones/PIB* & 2.2 & 1.3 & 0.0 & 1.76 & 2.55 & 7.8 \\
\hline
\end{tabular}

* Millones de transacciones / Miles de Millones de dólares

1/ Cheques Compensados. Para Canadá incluye cheques de alto y bajo valor; para los EUA incluye Private Clearing Houses and Federal Reserve.

2/ P.I. - Pago Interbancario. Para Canadá incluye Paperless Credit Transfers y Direct debits, para los EUA incluye Private y Federal Reserve ACHs.

3/ Para México incluye SPEUA y SIAC, para Canadá incluye Large Value Transfer System, y para los EUA incluye CHIPS y Fedwire. 
El Cuadro 4 presenta la estructura de pagos distintos al efectivo en términos del número de transacciones para 1999. En el cuadro se aprecia la dramática diferencia que existe entre el número de transacciones distintas al efectivo en México y en el resto de Norteamérica, independientemente de la medida que se utilice. En términos del total de transacciones, los datos para México representan apenas $1.17 \%$ y $4.5 \%$ de los correspondientes a los Estados Unidos y Canadá, respectivamente. En cuanto al número de transacciones per cápita, mientras que el mexicano promedio realizó 9.4 transacciones utilizando un medio de pago distinto al efectivo, el estadounidense y el canadiense promedio realizaron 289.5 y 165.5 transacciones respectivamente. En términos del valor del PIB, mientras en México se realizaron 1.9 transacciones sin efectivo por cada mil dólares de producto, en los Estados Unidos y Canadá se efectuaron 8.6 y 7.4 transacciones sin efectivo por cada mil dólares del PIB.

A continuación se presentan algunos otros elementos relevantes:

- El número de cheques compensados ${ }^{43}$ en México representó $0.45 \%$ y $14.1 \%$ de los correspondientes a los Estados Unidos y Canadá, respectivamente. En términos per cápita, mientras el mexicano promedio liquidó 2 cheques en 1999, el estadounidense promedio liquidó 175.4 y el canadiense 46.3 cheques en el mismo año. Dados estos datos per cápita, los cheques en los Estados Unidos representaron $60.6 \%$ de las transacciones totales, mientras que en Canadá y México constituyeron 28\% y 21.2\% respectivamente. El que los cheques hayan representado una fracción menor del número total de transacciones sin efectivo, con respecto a los Estados Unidos, es una característica positiva de los sistemas mexicano y canadiense ya que el proceso de los cheques tiene un alto costo con respecto a otros medios de pago. En el caso de los Estados Unidos, la alta utilización del cheque obedece a la inercia existente en el uso de este instrumento. En cuanto a México, la sustitución de cheques de alto valor se ha visto favorecida por el hecho de que el uso de cheques nunca llegó a ser tan difundido como en los Estados Unidos. Esto se relaciona tanto con la falta de profundidad del sistema financiero mexicano, como con las ya mencionadas limitaciones del sistema legal que no han favorecido a este instrumento de pago.

\footnotetext{
${ }^{43}$ Se trata de cheques liquidados, no de cheques emitidos para los 3 países.
} 
- El número de transferencias de alto valor en México representó solamente $2 \%$ de las de los Estados Unidos. Sin embargo, esa cifra es mayor que la existente en Canadá, a pesar de la diferencia en tamaño en las respectivas economías. Esto obedece a que el sistema de pagos de alto valor fue introducido en Canadá apenas en 1999. En cuanto a las transacciones de alto valor por persona, el mexicano promedio efectuó 0.03 transacciones en 1999, mientras que en los Estados Unidos y Canadá fueron 0.6 y 0.1, respectivamente. Es decir, si hubiera habido una transferencia de alto valor por persona en México, habría habido 18 en los Estados Unidos y 3 en Canadá.

- La brecha en pagos interbancarios es aún más notable. Mientras en México dichos pagos representan $0.2 \%$ del número total de pagos distintos al efectivo, en los Estados Unidos y Canadá dichos pagos significan $5.9 \%$ y $4.1 \%$, respectivamente.

- En cuanto al número absoluto de transacciones con tarjeta de crédito, en México representaron menos de $1 \%$ de las realizadas en los Estados Unidos y $12.1 \%$ de las llevadas a cabo en Canadá. Esto implica que cada mexicano realizó 1.4 transacciones en 1999, mientras que el estadounidense y el canadiense promedio efectuaron 68.8 y 37.6, respectivamente. De este modo, las transacciones con tarjeta de crédito en México en 1999 representaron 5.7\% del total de las transacciones sin efectivo, en tanto que para los Estados Unidos y Canadá, fueron 23.8\% y $22.7 \%$, respectivamente.

- La mayor parte de las transacciones sin efectivo en México se realizaron con tarjetas de débito; dichas transacciones representaron $62.6 \%$ del número total de transacciones, mientras que en los Estados Unidos y Canadá significaron 9.5\% y 32.9\%, respectivamente. Esto constituye evidencia de que la tarjeta de débito es aún un medio poco favorecido por los estadounidenses. Sin embargo, en términos de transacciones per cápita, mientras el mexicano promedió efectuó 6 transacciones con tarjeta de débito, el estadounidense y el canadiense promedio llevaron a cabo 28 y 55 , respectivamente.

El Cuadro 5 presenta la comparación internacional en términos del valor de las transacciones. Las cifras están expresadas en dólares de los Estados Unidos y corresponden a 1999. Lo primero que salta a la vista es que el valor absoluto de las transacciones sin efectivo en México representó apenas $1.3 \%$ del valor de los Estados Unidos y 24.9\% del de Canadá. Para corregir por el tamaño de las economías respectivas, se expresaron las cifras como proporción del PIB de cada país. Se 
aprecia que mientras el valor de las transacciones distintas a efectivo en México era 20 veces el tamaño del producto, los datos correspondientes en los Estados Unidos y en Canadá eran 77.1 y 58.2 veces el valor de sus PIB respectivos. En cuanto al valor de las transacciones sin efectivo por persona, el Cuadro 5 muestra que cada mexicano llevó a cabo operaciones por un valor de 96,700 dólares, mientras que un estadounidense y un canadiense realizaron operaciones por 2,624,000 dólares y por 1,241,000 dólares respectivamente. Esto significa que el valor por persona de las transacciones sin efectivo en los Estados Unidos y en Canadá fue 27 y 13 veces mayor que en México, respectivamente. Estas cifras resultan muy elevadas porque incluyen las transacciones de alto valor. Excluyendo las transacciones de alto valor, el mexicano promedio realizó pagos con medios distintos al efectivo por un monto de 2,978.3 dólares, mientras que el canadiense y el estadounidense promedio efectuaron pagos por 748,730.7 y 276,553.6 respectivamente. Esto recalca las enormes disparidades existentes en el uso de medios de pago distintos al efectivo entre México y el resto de Norteamérica.

\section{Cuadro 5}

Valor de las Transacciones sin Efectivo en Norteamérica (Cifras para 1999)

\begin{tabular}{|c|l|r|r|r|r|r|r|}
\hline \multicolumn{2}{|c|}{} & Cheques1 & P. I.2 & $\begin{array}{c}\text { Alto } \\
\text { Valor3 }\end{array}$ & $\begin{array}{c}\text { T. de } \\
\text { Crédito }\end{array}$ & T. de Débito & Total \\
\hline \multirow{3}{*}{ México } & Miles de millones de dólares & 241.0 & 9.1 & $9,122.4$ & 7.7 & 32.2 & $9,412.4$ \\
& Estructura (\%) & 2.6 & 0.1 & 96.9 & 0.08 & 0.34 & 100.0 \\
& Transacciones per cápita * & 2.5 & 0.094 & 93.7 & 0.08 & 0.33 & 96.7 \\
& Valor de Transacciones/PIB & 0.5 & 0.020 & 19.6 & 0.02 & 0.07 & 20.2 \\
\hline \hline \multirow{3}{*}{ EUA } & Miles de millones de dólares & $58,487.7$ & $15,426.2$ & $641,315.4$ & $1,290.3$ & 322.6 & $716,842.2$ \\
& Estructura (\%) & 8.2 & 2.2 & 89.5 & 0.18 & 0.05 & 100.0 \\
& Transacciones per cápita * & 214.2 & 56.5 & $2,348.3$ & 4.72 & 1.18 & $2,624.8$ \\
& Valor de Transacciones/PIB & 6.3 & 1.7 & 69.0 & 0.14 & 0.03 & 77.1 \\
\hline \multirow{3}{*}{ Canadán } & Miles de millones de dólares & $4,236.3$ & $18,478.2$ & $15,035.0$ & 72.8 & 48.9 & $37,871.2$ \\
& Estructura (\%) & 11.2 & 48.8 & 39.7 & 0.19 & 0.13 & 100.0 \\
& Transacciones per cápita * & 138.9 & 605.8 & 492.9 & 2.39 & 1.60 & $1,241.7$ \\
& Valor de Transacciones/PIB & 6.5 & 28.4 & 23.1 & 0.11 & 0.08 & 58.2 \\
\hline
\end{tabular}

\footnotetext{
* en miles

1/ Para los EUA el valor total de cheques compensados no está disponible, el valor de cheques compensados por la FED es $14,123.2$ miles de millones de dólares (el número total de cheques compensados fue de 47,891.7 millones), y el valor total de cheques emitidos es de 83,045 miles de millones (el número total de cheques emitidos fue de 68,000 millones), el valor total compensado que se reporta fue estimado con esta información.

2/ Para Canadá incluye Paperless Credit Transfers y Direct debits, para los EUA incluye Private y Federal Reserve ACHs.

3/ Para México incluye SPEUA y SIAC, para Canadá incluye Large Value Transfer System, y para los EUA incluye CHIPS y Fedwire.
}

A continuación se presentan algunos otros elementos relevantes en esta comparación:

- Para México y los Estados Unidos, las transferencias electrónicas de alto valor representaron 96.9\% y $89.5 \%$ respectivamente del valor total, mientras que para Canadá esa proporción fue 
de $39.7 \%$. Como se señaló antes, esto obedeció a que el sistema de transferencias de alto valor fue introducido en Canadá apenas en 1999.

- En cuanto al valor de las transacciones con tarjeta de crédito, cada mexicano realizó transacciones por 800 dólares en 1999, mientras el valor per cápita para los Estados Unidos y Canadá fue de 4,720 y de 2,390 dólares, respectivamente.

- Las diferencias en el valor per cápita de las transacciones realizadas con tarjeta de débito son mucho menos dramáticas. El mexicano promedió realizó pagos con tarjeta de débito por 330 dólares en 1999, mientras que el estadounidense y el canadiense promedio pagaron con tarjeta de débito 1,180 y 1,600 dólares, respectivamente.

En suma, a pesar de la creciente importancia que los medios de pago no tradicionales distintos al efectivo han adquirido en México, su uso es aún significativamente menor que el observado en los otros países de Norteamérica. Sin embargo, esto no necesariamente significa que los sistemas de pago no tradicionales estén menos desarrollados en México que en los Estados Unidos y Canadá. La importancia relativa de los medios de pago distintos al efectivo entre México y el resto de Norteamérica está relacionada con la diferencia en la profundidad de los respectivos sistemas financieros. En México, el acceso al sistema financiero es aún bastante limitado; dicho acceso es necesario para que los individuos y las empresas puedan utilizar medios de pago distintos al efectivo. En estas condiciones, a pesar de que México cuenta con un sistema de pagos distinto al efectivo poco extendido respecto a otros países industrializados, dicho sistema parece estar suficientemente desarrollado para enfrentar las necesidades actuales del sistema financiero mexicano. 


\section{Conclusión}

El análisis presentado en este trabajo muestra que el número total de transacciones de alto volumen distintas al efectivo en México, se duplicó de 1997 a 2000; a pesar de ello, en términos del valor de esas transacciones, el incremento fue modesto. Esta evolución es resultado de un mayor uso de los medios de pago no tradicionales, como las tarjetas de débito y el Pago Interbancario. Paralelamente, los medios de pago tradicionales, como los cheques y las tarjetas de crédito, perdieron terreno en la estructura. Este cambio resulta de la combinación de varios factores. Por un lado, los cheques y las tarjetas de crédito implican un mayor riesgo que las tarjetas de débito y las transferencias electrónicas. En estos últimos casos, la transferencia se efectúan sólo si existen recursos del agente que efectúa el pago. Por otro lado, la falta de un sistema legal que permita un castigo expedito y una rápida solución a los problemas de pago perjudica el uso de cheques y tarjetas de crédito, los cuales están sujetos a un mayor riesgo.

Las reformas a los sistemas de pago tuvieron un efecto importante en la forma en la que se realizan las transacciones de alto valor en México. Así, las transacciones en cheque han sido en muy buena parte sustituidas por medios electrónicos. Además, se ha logrado reducir en forma importante el riesgo sistémico. En particular se observa que, en términos del número de transacciones, el SPEUA continúa creciendo. Sin embargo, en términos de valor, el SPEUA ha permanecido prácticamente estancado en los últimos años. De este modo, la estructura porcentual de valor de las transacciones al mayoreo se ha mantenido constante. El elevado valor y número de transacciones que estos sistemas han alcanzado en un plazo relativamente corto, refleja el éxito de la reforma del sistema de pagos.

En general se puede decir que los sistemas de pago en México cuentan con una infraestructura adecuada. Sin embargo, a pesar del reciente incremento, su utilización en México es aún muy reducida con respecto a lo que se observa en los Estados Unidos y Canadá. Esta diferencia no es sólo imputable a una tardía adopción de los sistemas y medios de pago distintos al efectivo. En una forma importante, esto último se relaciona con el limitado acceso al sistema financiero que posee una elevada proporción de la población mexicana. 


\section{Referencias}

Banco de México 2001. "Sistemas de Pagos en México", documento interno, DGOBC.

Bank for International Settlements 1999. Retail Payments in Selected Countries: A comparative Study, Basle, Switzerland, September.

Bank for International Settlements (BIS), Committee on Payment and Settlement Systems 2000. Statistics on Payments Systems in the Group of Ten Countries, Basle, Switzerland, February.

Belton, Terrence M. 1987. "Daylight Overdrafts and the Payment System Risk", Federal Reserve Bulletin, November.

Boeschoten, W. 1992. Currency use and Payment Patterns. Financial and Monetary Policy Studies, vol.23. Klwer Academic Publishers, Norwell, MA.

Carnet-Prosa, 1990. El Dinero de plástico, Historia del Crédito al consumidor y de los nuevos sistemas de Pago en México, México Ed. J.R. Fortson.

Chakravorti, Suji, 1997. "Mexican Payments System Reforms". Financial Industry Studies, Federal Reserve Bank of Dallas, August, 12-22.

Evans, David and Richard Schmalensee (1999). Paying with Plastic. MIT Press.

Figueroa-Silva, Sylvana, 1995. Características y Funcionamiento de las tarjetas de crédito en México. Aplicación documental. Tesina ITAM, México D.F.

Hanckoc, Diana and David B. Humphrey, 1998. "Payment transactions, instruments, and systems: A survey". Journal of Banking and Finance 21, 1573-1624.

Jallath, Eduardo, 2000. An Empirical Evaluation of an Inter-bank Electronic Payment System, Doctoral Dissertation, Carnegie Mellon University.

Negrin, Jose L. and Lorenza Martinez, 2000. "Characteristics of Credit Card Users in Mexico: A Microeconomic Approach". Banco de Mexico, Mimeo.

Rogers, E. 1995. Diffusion and Innovations, $4^{\text {th }}$ Edition, The Free Press.

Sánchez-Arroyo, Abdón, 1996. “The Mexican Payment and Settlement System: The Quality and Quantity Leaps Ahead", The North American Journal of Economic and Finance 7(2): 171-79.

Schwartz, Moisés 1998. "Consideraciones sobre la Instrumentación Práctica de la Política Monetaria”, Documento de Investigación 9804 Banco de México.

US Treasury Department, 2000. The Use of Counterfeiting of US Currency Abroad. January.

VanHoose, David D. Sellon, and Gordon H., 1989. "Daylight Overdrafts, Payments System Risk, and Public Policy", Economic Review, September October.

Weiner, Stuart, 1999. "Electronic Payments in the U.S. Economy: An Overview", Economic Review, Federal Reserve Bank of Kansas City, Fourth Quarter,1-12. 